\title{
Use of contraceptive depot medroxyprogesterone acetate is associated with impaired cervicovaginal mucosal integrity
}

Irina A. Zalenskaya, ${ }^{1}$ Neelima Chandra, ${ }^{1}$ Nazita Yousefieh, ${ }^{1}$ Xi Fang, ${ }^{1}$ Oluwatosin E. Adedipe, ${ }^{1}$ Suzanne S. Jackson, ${ }^{1}$ Sharon M. Anderson, ${ }^{1}$ Christine K. Mauck, ${ }^{2}$ Jill L. Schwartz, ${ }^{2}$ Andrea R. Thurman, ${ }^{1}$ and Gustavo F. Doncel ${ }^{1,2}$

'CONRAD, Eastern Virginia Medical School, Norfolk, Virginia, USA. 'CONRAD, Eastern Virginia Medical School, Arlington, Virginia, USA

\begin{abstract}
BACKGROUND. Injectable depot medroxyprogesterone acetate (DMPA) is one of the most popular contraception methods in areas of high HIV seroprevalence. Evidence is accumulating that use of DMPA might be associated with an increased risk of HIV-1 acquisition by women; however, mechanisms of this association are not completely understood. The goal of this study was to gain insight into mechanisms underlying the possible link between use of DMPA and risk of HIV-1 acquisition, exploring transcription profiling of ectocervical tissues.
\end{abstract}

METHODS. Healthy women received either DMPA ( $n=31$ ) or combined oral contraceptive (COC), which has not been linked to an increased risk of HIV acquisition $(n=32$ ). We conducted a comparative microarray-based whole-genome transcriptome profiling of human ectocervical tissues before and after 6 weeks of hormonal contraception use.

RESULTS. The analysis identified that expression of 235 and 76 genes was significantly altered after DMPA and COC use, respectively. The most striking effect of DMPA, but not COC, was significantly altered expression (mostly downregulation) of many genes strategically involved in the maintenance of mucosal barrier function; the alterations, as indicated by Ingenuity Pathway Analysis (IPA), were most likely due to the DMPA-induced estrogen deficiency. Furthermore, IPA predicted that transcriptome alterations related to ectocervical immune responses were in general compatible with an immunosuppressive effect of DMPA, but, in some women, also with an inflammatory-like response.

CONCLUSION. Our results suggest that impairment of cervicovaginal mucosal integrity in response to DMPA administration is an important mechanism contributing to the potential increased risk of HIV-1 acquisition in DMPA users.

TRIAL REGISTRATION. ClinicalTrials.gov NCT01421368.

FUNDING. This study was supported by the United States Agency for International Development (USAID) under Cooperative Agreement GPO-A-00-08-00005-00.

\section{Introduction}

Hormonal contraceptive (HC) methods are affordable and highly effective for prevention of unintended pregnancy. However, evidence is accumulating that some types of $\mathrm{HC}$, particularly injectable medroxyprogesterone acetate (MPA), referred to as depot MPA (DMPA; Depo-Provera), might be associated with an increased risk of HIV-1 acquisition by women. The first reports about a potential effect of HC on HIV-1 acquisition date over 2 decades back $(1,2)$. Since that time, the potential association between $\mathrm{HC}$ use and risk of HIV-1 acquisition has been investigated in more than 30 epidemiological studies; however, findings from these studies remain inconsistent (reviewed in refs. 3-7).

Authorship note: NC and NY contributed equally to this work Conflict of interest: The authors have declared that no conflict of interest exists. Submitted: February 19, 2018; Accepted: July 31, 2018.

Reference information: J Clin Invest. 2018;128(10):4622-4638.

https://doi.org/10.1172/JCl120583.
In several recent high-quality meta-analyses of the epidemiological data, DMPA use was estimated to increase a woman's risk of acquiring HIV 1.4 to 1.5 times in comparison with women not using HC, while no statistically significant positive association between HIV acquisition and use of combined oral contraceptive (COC) pills or the injectable progestin norethisterone enanthate has been found (3-6). Even higher effects of DMPA on risk of HIV acquisition were reported in studies on women already at high risk of infection $(8,9)$.

These results strengthened concerns about the safety of DMPA, particularly in countries of eastern and southern Africa, where injectable progestins are the most popular contraceptive methods, accounting for over $40 \%$ of contraception use (10), and the number of women using these methods is rapidly increasing.

However, a withdrawal of DMPA from family planning programs or even a shift to other contraceptive methods may have a substantial detrimental effect on maternal and infant morbidity and mortality rates (11). The interaction between effective family planning and effective HIV prevention is a complicated matter that 


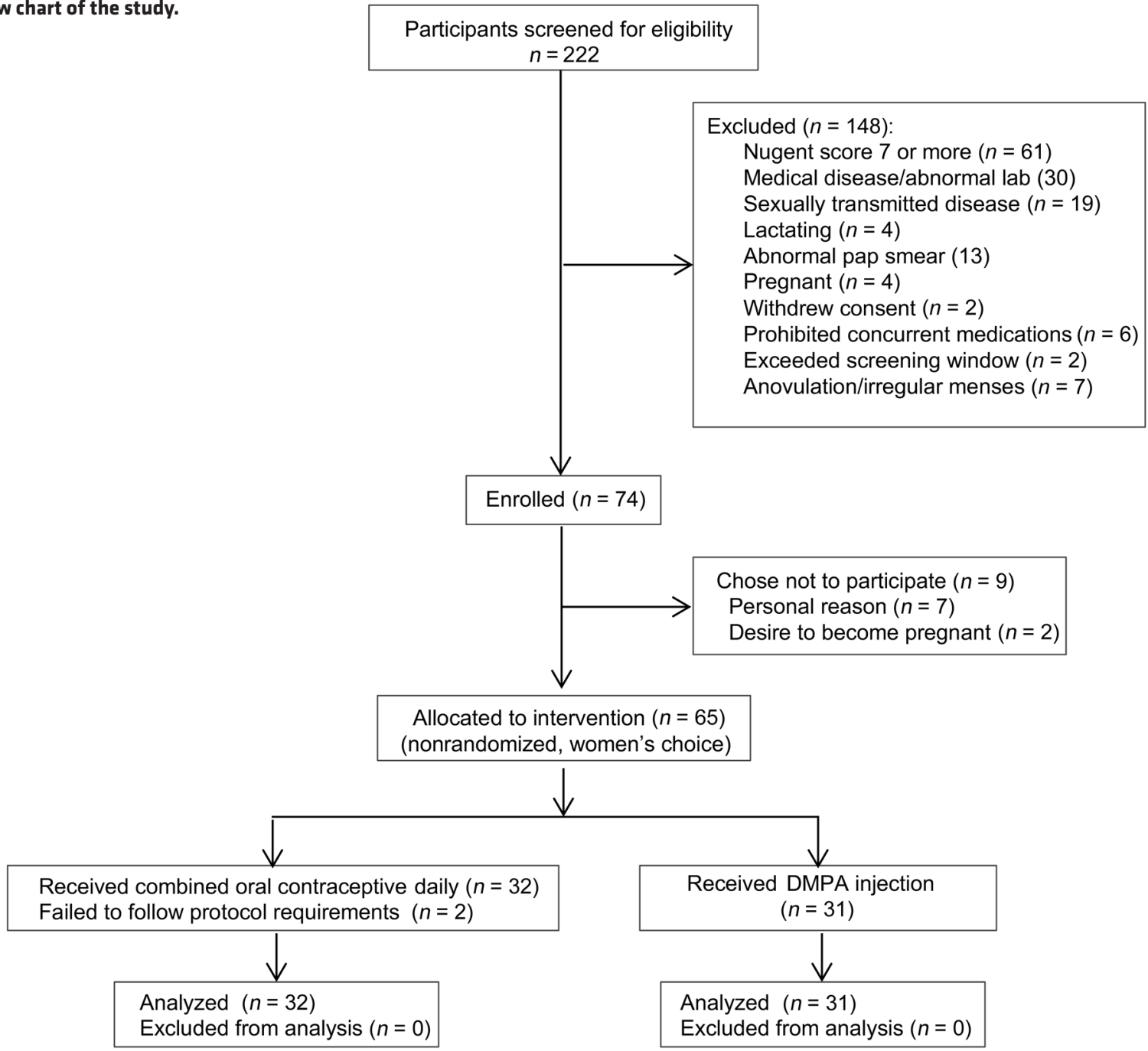

requires in-depth examination. To this end, the ECHO (Evidence for Contraceptive Options and HIV Outcomes) trial, designed to determine the impact of type of contraceptive on risk of HIV acquisition, is currently ongoing (http://echo-consortium.com). Furthermore, understanding mechanisms that could explain the potential association between enhanced risk of acquiring HIV and use of DMPA would help in determining best prevention practices.

Several plausible biological mechanisms have been proposed to explain the potential link between DMPA use and increased risk of HIV-1 vaginal transmission (reviewed in refs. 5, 12-17). They include elevated levels of cervicovaginal inflammatory mediators (18-22) that may cause activation of HIV-1 target cells and their recruitment to the cervicovaginal mucosa $(8,23-25)$, suppression of protective systemic and local innate and adaptive immunity (21, 26-31), alteration in the vaginal microbiota composition $(32,33)$, promotion of viral penetration by impairing mucosal repair (18, 28 ), and a direct effect of MPA on HIV replication and transcytosis $(26,34,35)$. However, data presented in these studies are not always in agreement.

To gain further insight into mechanisms underlying the potential link between use of injectable DMPA and risk of HIV-1 acquisition, we conducted a comparative whole-genome expression profiling of the ectocervical mucosa at baseline and after DMPA use or use of a COC, represented by a combination of the progestin levonorgestrel (LNG) and the synthetic estrogen ethinyl estradiol, which has not been associated with increased risk of HIV-1 acquisition. This study demonstrates that DMPA use results in significant alteration in expression of ectocervical genes essential for mucosal barrier structure and function and, as predicted by functional analysis of the differentially expressed genes, that estrogen deficiency is a driving force for such alterations. We also demonstrate distinct, clustered diversity in the gene expression response to DMPA administration among participants.

\section{Results}

Characteristics of participants at baseline. This open-label nonrandomized study included 63 healthy women who chose to receive either DMPA injection $(n=31)$ or COC $(n=32)$ (Figure 1 and Table 1). DMPA users had higher BMI and included significantly fewer participants of Hispanic ethnicity than the COC group. Among 18 enrolled black women, the majority of them chose to receive DMPA $(P=0.08)$.

Ectocervical transcriptomes did not display significant differences between DMPA and COC groups at baseline. In addition to 
Table 1. Demographic and clinical characteristics of participants at enrollment

\begin{tabular}{|c|c|c|c|}
\hline Characteristics & DMPA users $(n=31)$ & COC users $(n=32)$ & $P$ value ${ }^{A}$ \\
\hline Age, years, mean (SD) & $33.7(7.6)$ & $30.2(8.3)$ & 0.07 \\
\hline Race, $n(\%)$ & & & 0.22 \\
\hline Black & $12(38.7)$ & $6(18.8)$ & \\
\hline White & $9(29.0)$ & $16(50.0)$ & \\
\hline Asian & $0(0)$ & $1(3.1)$ & \\
\hline Mixed and other race & $10(32.3)$ & $9(28.1)$ & \\
\hline Hispanic, $n(\%)$ & $10(32.2)$ & $21(65.6)$ & 0.01 \\
\hline $\mathrm{BMI}^{\mathrm{B}}$, mean (SD) & $32.9(8.2)$ & $27.5(6.9)$ & $<0.01$ \\
\hline Sexual partner status, $n(\%)$ & & & 0.35 \\
\hline Lives with partner & $13(41.9)$ & $19(59.4)$ & \\
\hline Does not live with partner & $15(48.4)$ & $10(31.3)$ & \\
\hline No partner & $3(9.7)$ & $3(9.4)$ & \\
\hline Sexual relationship, years (SD) & $7.4(6.5)$ & $5.5(5.8)$ & \\
\hline Years of education, mean (SD) & $13.3(3.3)$ & $14.0(3.3)$ & \\
\hline \multicolumn{4}{|c|}{$\begin{array}{l}\text { AContinuous values were compared using } 2 \text {-tailed } t \text { test for normally distributed data or } \\
\text { Mann-Whitney for non-normally distributed data; for categorical data, Fisher's exact tests } \\
\text { or } \chi^{2} \text { statistics were used. }{ }^{B} \text { The BMI is the weight in kilograms divided by the square of } \\
\text { height in meters. }\end{array}$} \\
\hline
\end{tabular}

DEGs that were found downregulated in the ectocervical tissues of DMPA users are involved in epithelial barrier function and differentiation (Table 2).

The top most downregulated and the most statistically significant DEG was a member of the epidermal differentiation complex (EDC) - repetin $\left(R P T N ; \mathrm{FC}=-6.83, P<1 \times 10^{-7}\right)$ (Table 2 and Supplemental Table 1). DMPA use caused downregulation of other genes belonging to the EDC: late cornified envelope 3D (LCE3D), loricrin ( $L O R)$, and small proline-rich protein 2C (SPRR2C). Also downregulated were genes critical for development of the stratum corneum of the epidermis: transglutaminase 3 (TGM3) and arachidonate 12-lipooxygenase, 12R type $(A L O X 12 B)$. The list of significantly downregulated DEGs included genes encoding cell junctional proteins: the desmosomal cadherins desmoglein 1 (DSG1) and desmocollin 2 (DSC2) and the corneodesmosomal protein corneodesmosin (CDSN). In addition, we observed changes in gene expression of keratinocyte differentiation markers, including downregulation of keratin 10 (KRT10) and KRT1, as well as upregulation of KRT18 and KRT19. A desmoclinical characteristics, we conducted a comparison of ectocervical gene expression between HC groups at baseline. The analysis identified only 5 differentially expressed genes (DEGs), with false discovery rate-adjusted $P$ value set at 0.05 , between DMPA and COC cohorts at this point (Supplemental Table 1; supplemental material available online with this article; https://doi. org/10.1172/JCI120583DS1). None of these genes was found to be differentially expressed after HC use compared with baseline (Supplemental Tables 2 and 3).

DMPA but not COC use resulted in substantial changes in ectocervical gene expression. Transcriptional analysis of ectocervical tissues before and after use of $\mathrm{HC}$ revealed that, in comparison with baseline, DMPA use caused statistically significant changes in expression of 235 genes (Supplemental Table 2). Of these, 56 DEGs were upregulated, with fold change (FC) ranging from +1.24 to +4.5 , while 179 DEGs were downregulated, with FC ranging from -1.21 to -6.83 . The effect of COC on the ectocervical mucosa was markedly less evident - only 76 genes were differentially expressed (Supplemental Table 3): 12 DEGs were upregulated and 64 DEGs were downregulated. Expression changes in the COC group were much smaller in magnitude than those in the DMPA group: FC ranged from +1.31 to +1.81 for upregulation and from -1.23 to -1.83 for downregulation. In the DMPA group, expression of 27 genes was altered at least 2-fold; of these, changes in 22 genes were statistically significant at parametric $P<0.001$ (8 upregulated, 14 downregulated) (Table 2 and Supplemental Table 1). None of the genes reached 2-fold expression change after COC use. Of 76 genes changed by COC, 20 were also altered by DMPA (Supplemental Table 4).

Unsupervised hierarchical clustering analysis based on DMPAaltered genes demonstrated good separation between baseline and DMPA usage (Figure 2A). The distinction based on COC-altered genes was less evident (Figure 2B).

DMPA use was associated with altered expression of genes involved in the maintenance of epithelial integrity and differentiation. Many somal cadherin defect and dramatic loss of KRT10 at the protein level were also detected in the vaginal mucosa (Figure 3). DSG1 protein was seen as a sharp border outlining suprabasal vaginal keratinocytes in the baseline samples, while the outline was lost after DMPA use. Levels and patterns of distribution of KRT10 and DSG1 remained unchanged after COC use. Deficiency in desmosomal and corneodesmosomal proteins might also be due to downregulation in DMPA users of serine peptidase inhibitor clade B, member 7 (SERPINB7), and serine protease inhibitor, Kazal type 6 (SPINK6), which are known to inhibit kallikreinrelated (KLK) peptidases that specifically degrade cell junctions $(36,37)$. Furthermore, loss of DSG1 may be heightened by upregulation of proteinase calpain 14 (CAPN14) (38). Among other suppressed genes implicated in epithelial barrier function were the suprabasal keratinocyte-secreted proteins dermokine $(D M K N)$ and suprabasin $(S B S N)$. The loss of DMKN at a protein level was also demonstrated in the vaginal epithelium of DMPA users (Supplemental Figure 1).

Interestingly, we observed changes in expression of genes encoding enzymes that regulate the level of retinoic acid (RA), which is known to affect KRT10 and DSG1 expression and keratinocyte differentiation $(39,40)$. These enzymes included cytochrome P450 family 26, subfamily B, polypeptide 1 (CYP26B1), which was downregulated with the highest statistical significance $\left(P<1 \times 10^{-7}\right)$, and retinol dehydrogenase 10 ( $R D H 10)$, which was upregulated.

Notably, DMPA use caused significant downregulation of progesterone receptor gene $(P G R)$ in ectocervical tissue.

DEGs upregulated by DMPA encode multifunctional proteins. DEGs highly upregulated by DMPA included olfactomedin 4 (OLFM4), $\gamma$-aminobutyric acid receptor, pi $(G A B R P)$, dual-specificity phosphatase 4 (DUSP4), protocadherin 8 (PCDH8), and steroid sulfatase, isozyme S (STS) (Table 2). These genes encode multiroids including estrogen (Supplemental Table 5 and ref. 41). functional proteins, which may regulate or be regulated by sex ste- 


\section{Table 2. Genes most significantly differentially expressed ( $[\mathrm{FC}] \geq 2$ ) and selected genes associated with epithelial barrier function in cervical epithelium after DMPA use}

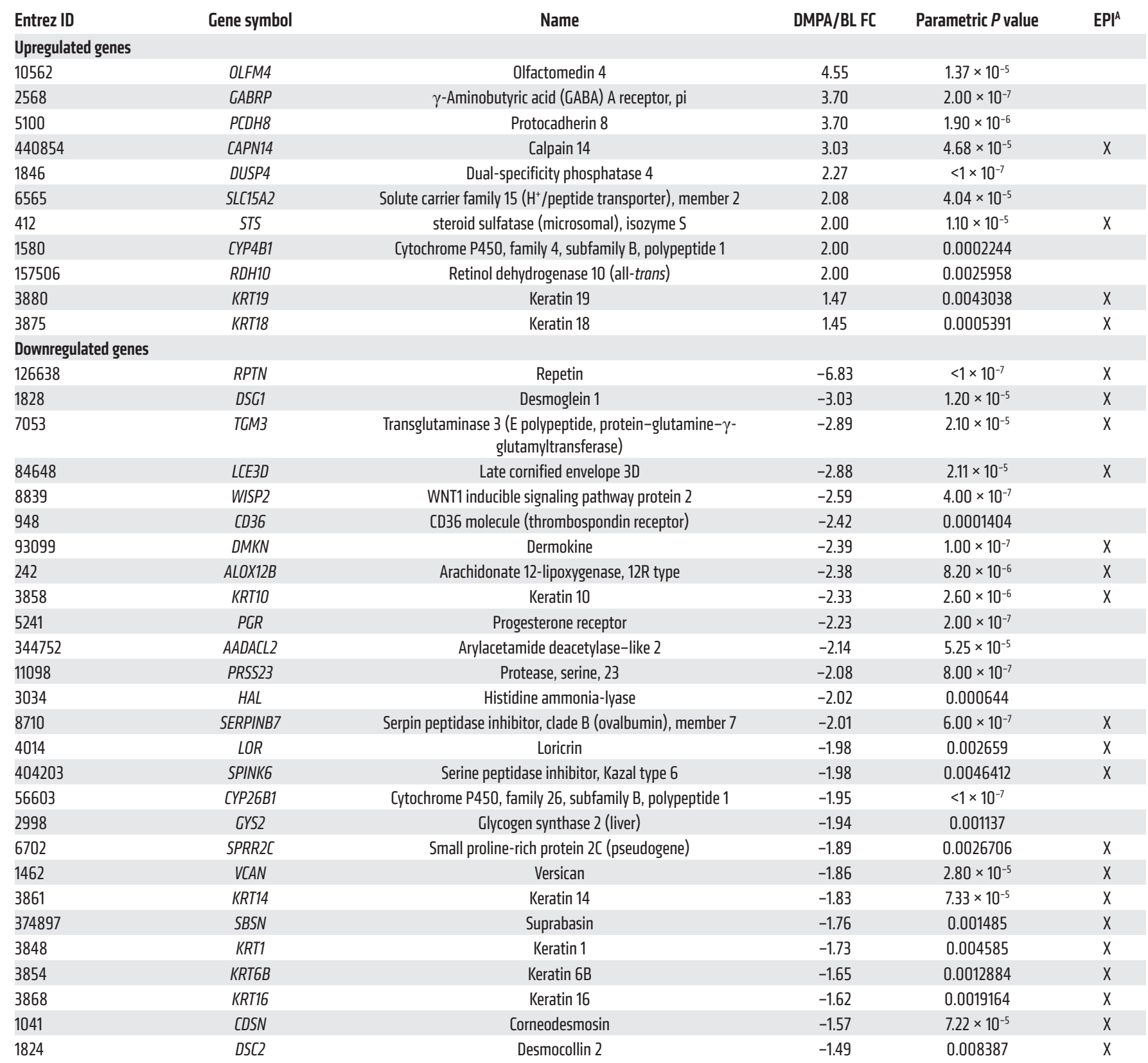

${ }^{A} E P I$ indicates genes encoding proteins associated with epidermal/epithelial differentiation and barrier function (based on functional analysis and published literature).

Changes in expression of several genes selected based on their function were confirmed by quantitative reverse transcriptase PCR (Supplemental Figure 2 and Supplemental Table 6).

Expression of epithelial barrier genes displayed strong positive intragroup correlation and negative correlation with upregulated genes. We were interested to see how differentially expressed genes and specifically those involved in the epithelial functions were coordinated with each other and with other significant genes.

We performed statistical correlation analysis for 20 genes, selected based on their expression level and/or involvement in epithelial barrier functions. We found that genes associated with epithelial structure such as RPTN, DSG1, ALOX12B, DMKN, LCE3D, TGM3, and KRT1O displayed strong positive correlation in expression among each other (Figure 4), with $P<0.001$ for all of them and $P<0.0001$ for most of them (Supplemental Figure 3). These genes also strongly correlated with CYP26B1 and, except for KRT10, with glycogen synthase 2 (GYS2). Significant negative correlation (with some exceptions; see Figure 4) was observed between epithelial barrier genes (RPTN, DSG1, ALOX12B, DMKN, and $K R T 10$ ) and genes that were found to be strongly upregulated 

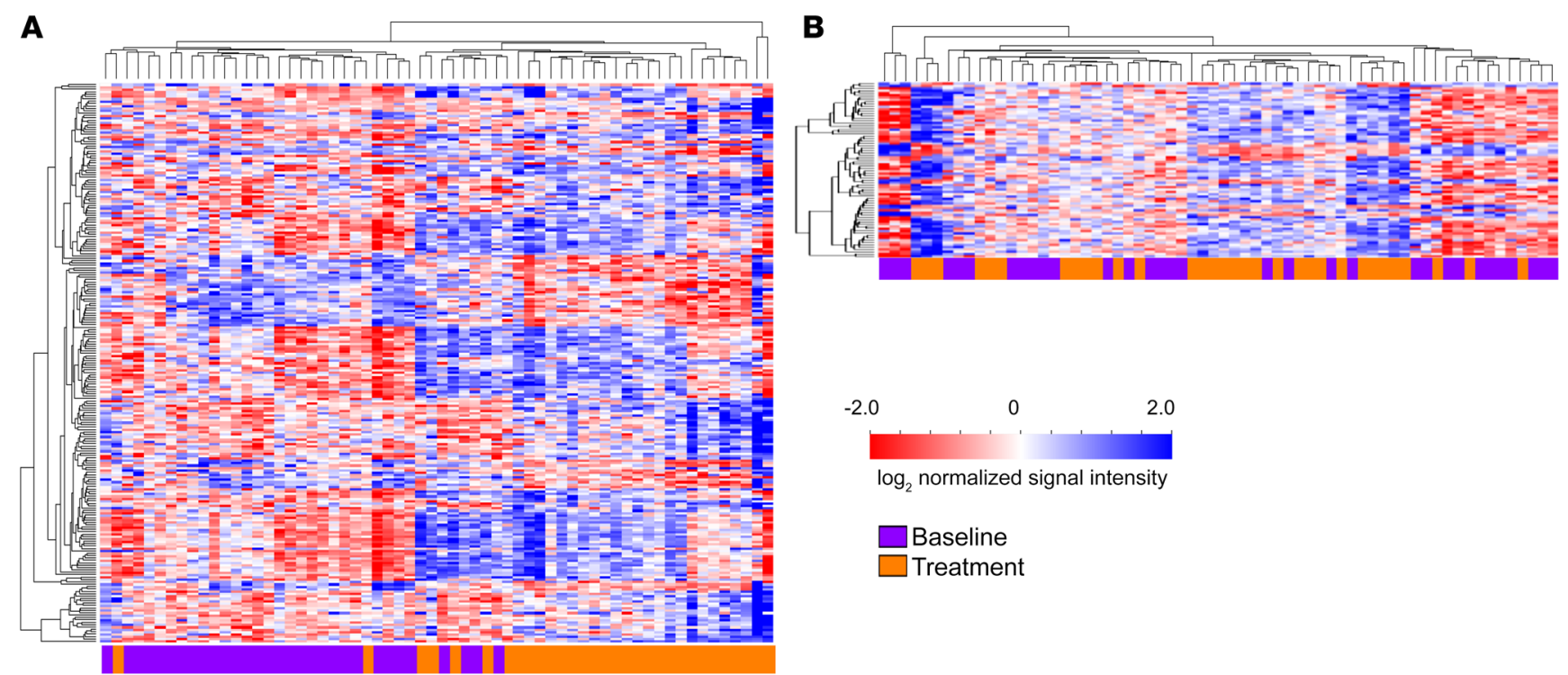

Baseline

Treatment

Figure 2. Heatmaps of hierarchical clustering of the genes differentially expressed in the ectocervical epithelium of hormone contraception users. (A) DMPA users. (B) COC users. Columns represent participants; rows represent genes. Gene expression levels are indicated by color: red denotes upregulation; blue denotes downregulation.

(GABRP, DUSP4, STS, OLFM4, and PCDH8). These upregulated genes were positively correlated with each other. There was a significant positive correlation $(P<0.0001)$ between each other for $P G R$, serine protease 23 (PRSS23), WNT1 inducible signaling pathway protein 2 (WISP2), versican (VCAN), and also CYP26B1, while these genes displayed strong negative correlation with GABRP and DUSP4. Interestingly, for PGR, PRSS23, WISP2, and $V C A N$ there was low correlation $(P>0.05)$ or no correlation with epithelial structural genes.

Functional analysis revealed alterations in epidermal/epithelial structure as top biological functions enriched in DMPA but not COC users, while biological processes related to immune cell movement and functions were affected in both groups. Strengthening and expanding gene expression results discussed in the previous section, Ingenuity Pathway Analysis (IPA) indicated that the top overrepresented function in DEGs after DMPA use was "dermatological diseases and conditions," which involved 148 genes (Figure 5A and Supplemental Figure 4A). In DEGs of the COC group, this function was the least significant; the top enriched function in the COC group was "cellular movement" (33 DEGs) (Figure 5A and Supplemental Figure 4B). Overall, for almost all functions enriched in $\mathrm{HC}$ users, statistical significance was considerably stronger in the DMPA group. Functions with significance comparable between DMPA and COC were "cellular movement," "cellular growth and prolifera-

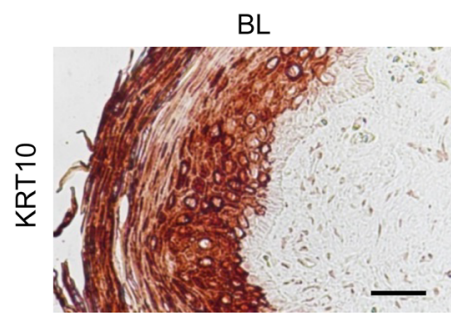

tion," and "cell-to-cell signaling and interaction." Using IPA, for some of the enriched functions it was possible to compute their predicted activation states, which are characterized by the activation $Z$ score, with absolute values of $Z$ scores $\geq 2$ being considered significant. In both contraception groups, the overwhelming majority of computable functions was predicted to be suppressed (negative $Z$ scores), notably including categories of immune cell movement and functions (Figure 5B and Supplemental Tables 7 and 8). In the DMPA group, they encompassed "leukocyte migration" ( $Z$ score $=-2.703$, number of molecules in the function $[n]$ $=31$ ), "recruitment of leukocytes" ( $Z$ score $=-2.215, n=15)$, "cell movement of leukocytes" ( $Z$ score $=-2.194, n=23)$, and "immune response of neutrophils" ( $Z$ score $=-2.4, n=6)$; and in the COC group, "cell movement" ( $Z$ score $=-2.519, n=32)$, "cell movement
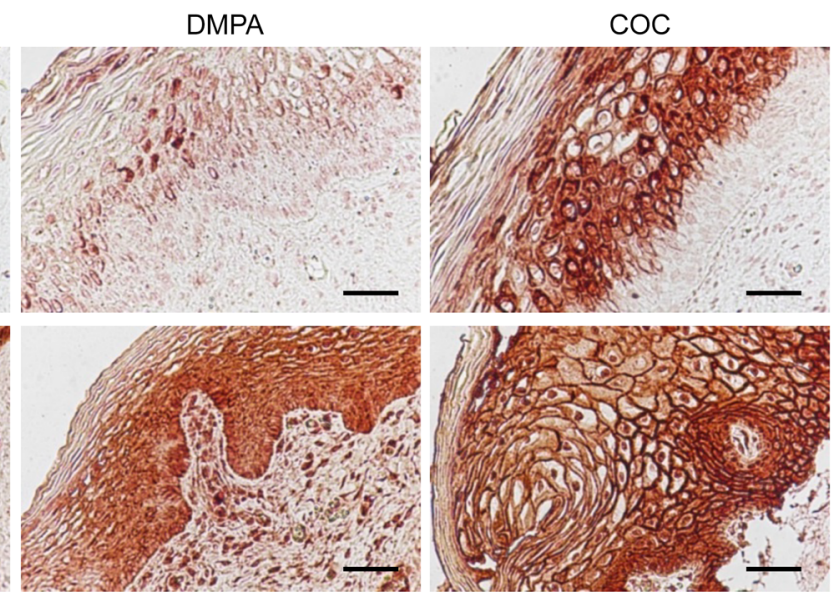

Figure 3. Representative images of immunohistochemical detection of KRT10 and DSG1 in the vaginal epithelium at baseline ( $n=10$ in DMPA cohort; $n=5$ in COC cohort) and after contraception use ( $n=16$ in DMPA cohort; $\boldsymbol{n}=\mathbf{5}$ in COC cohort). See Supplemental Figure 5 for more details. BL, baseline. Scale bars: $100 \mu \mathrm{m}$. 


\begin{tabular}{|c|c|c|c|c|c|c|c|c|c|c|c|c|c|c|c|c|c|c|c|c|}
\hline Symbol & $\frac{z}{\underline{\underline{n}}}$ & $\begin{array}{l}z \\
\sum_{\Delta}^{2}\end{array}$ & $\begin{array}{l}\stackrel{9}{N} \\
\underset{x}{x} \\
\stackrel{1}{\ll}\end{array}$ & $\begin{array}{l}\overline{0} \\
\text { D }\end{array}$ & $\begin{array}{l}0 \\
\text { ய } \\
\text { U }\end{array}$ & $\underset{\frac{\underline{x}}{\underline{\underline{x}}}}{\stackrel{ }{\frac{1}{2}}}$ & 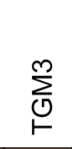 & $\underset{\widetilde{N}}{\stackrel{N}{\circlearrowright}}$ & 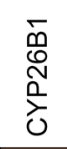 & $\begin{array}{l}\frac{r}{0} \\
0\end{array}$ & 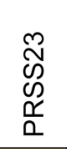 & $\frac{N}{\frac{N}{00}}$ & $\begin{array}{l}z \\
\text { d } \\
\text { S }\end{array}$ & 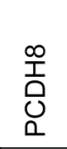 & $\begin{array}{l}\stackrel{ }{1} \\
\frac{1}{1} \\
\frac{1}{x}\end{array}$ & $\frac{\sum_{0}^{\nabla}}{\Delta}$ & $\begin{array}{l}\stackrel{+}{0} \\
\text { c) } \\
\stackrel{2}{0}\end{array}$ & $\frac{⿱ 亠 䒑}{z}$ & 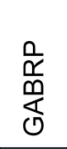 & $\stackrel{\omega}{\omega}$ \\
\hline RPTN & 1 & 0.8 & 0.79 & 0.74 & $|0.69|$ & 0.62 & 0.58 & 0.47 & 0.57 & 0.29 & 0.2 & 0.19 & 0.11 & -0.4 & -0.4 & -0.4 & -0.5 & -0.6 & -0.6 & -0.66 \\
\hline DMKN & 0.80 & 1.00 & 0.80 & 0.82 & $\mid 0.68$ & 0.69 & 0.54 & 0.61 & 0.60 & 0.30 & 0.37 & 0.25 & 0.24 & -0.40 & -0.5 & -0.46 & -0.46 & -0.56 & -0.58 & -0.64 \\
\hline ALOX12B & 0.79 & 0.80 & 1.00 & 0.70 & $\mid 0.62$ & 0.60 & 0.68 & 0.58 & 0.49 & 0.24 & 0.23 & 0.16 & 0.13 & -0.40 & -0.4 & -0.50 & -0.39 & -0.43 & -0.54 & -0.60 \\
\hline DSG1 & 0.74 & 0.82 & 0.70 & 1.00 & 0.61 & 0.63 & 0.46 & 0.54 & 0.53 & 0.18 & 0.26 & 0.18 & 0.13 & -0.27 & -0.6 & -0.42 & -0.49 & -0.63 & -0.59 & -0.72 \\
\hline LCE3D & 0.69 & 0.68 & 0.62 & 0.61 & $\mid 1.00$ & 0.41 & 0.63 & 0.75 & 0.42 & 0.10 & 0.11 & 0.09 & 0.02 & -0.36 & -0.3 & -0.40 & -0.19 & -0.49 & -0.34 & -0.51 \\
\hline KRT10 & 0.62 & 0.69 & 0.60 & 0.63 & $\mid 0.41$ & 1.00 & 0.44 & 0.22 & 0.58 & 0.30 & 0.34 & 0.28 & 0.26 & -0.34 & -0.5 & -0.37 & -0.64 & -0.41 & -0.58 & -0.49 \\
\hline TGM3 & 0.58 & 0.54 & 0.68 & 0.46 & $\mid 0.63$ & 0.44 & 1.00 & 0.54 & 0.42 & 0.17 & 0.16 & 0.15 & 0.06 & -0.59 & -0.3 & -0.60 & -0.36 & -0.38 & -0.45 & -0.54 \\
\hline GYS2 & 0.47 & 0.61 & 0.58 & 0.54 & 0.75 & 0.22 & 0.54 & 1.00 & 0.24 & $-0.05 \mid$ & 0.00 & -0.04 & -0.04 & -0.28 & $-0.22 \mid$ & -0.47 & -0.04 & -0.43 & -0.14 & -0.53 \\
\hline CYP26B1 & 0.57 & 0.60 & 0.49 & 0.53 & \begin{tabular}{|l|}
0.42 \\
\end{tabular} & 0.58 & 0.42 & 0.24 & 1.00 & 0.76 & 0.71 & 0.58 & 0.61 & -0.47 & -0.5 & -0.43 & -0.55 & -0.45 & -0.70 & -0.44 \\
\hline PGR & 0.29 & 0.30 & 0.24 & 0.18 & 0.10 & 0.30 & 0.17 & -0.05 & 0.76 & 1.00 & 0.85 & 0.82 & 0.83 & -0.49 & -0.3 & -0.33 & -0.50 & -0.25 & -0.65 & -0.17 \\
\hline PRSS23 & 0.20 & 0.37 & 0.23 & 0.26 & 0.11 & 0.34 & 0.16 & 0.00 & 0.71 & 0.85 & 1.00 & 0.86 & 0.84 & -0.45 & -0.3 & -0.29 & -0.46 & -0.27 & -0.60 & -0.14 \\
\hline WISP2 & 0.19 & 0.25 & 0.16 & 0.18 & 0.09 & 0.28 & 0.15 & -0.04 & 0.58 & 0.82 & 0.86 & 1.00 & 0.84 & -0.54 & -0.3 & -0.34 & -0.54 & -0.24 & -0.60 & -0.14 \\
\hline VCAN & 0.11 & 0.24 & 0.13 & 0.13 & 0.02 & 0.26 & 0.06 & -0.04 & 0.61 & 0.83 & 0.84 & 0.84 & 1.00 & -0.48 & -0.2 & -0.23 & -0.40 & -0.15 & -0.55 & -0.02 \\
\hline PCDH8 & -0.38 & -0.40 & -0.40 & $-0.27 \mid$ & -0.36 & -0.34 & -0.59 & -0.28 & -0.47 & -0.49 & -0.45 & -0.54 & -0.48 & 1.00 & 0.32 & 0.76 & 0.58 & 0.39 & 0.66 & 0.47 \\
\hline RDH10 & -0.4 & -0.5 & -0.4 & -0.6 & -0.3 & -0.5 & -0.3 & -0.2 & -0.5 & -0.3 & -0.3 & -0.3 & -0.2 & 0.32 & 1 & $\mid 0.47$ & 0.72 & 0.78 & 0.64 & 0.81 \\
\hline OLFM4 & -0.45 & -0.46 & -0.50 & -0.42 & -0.40 & -0.37 & -0.60 & -0.47 & -0.43 & -0.33 & -0.29 & -0.34 & -0.23 & 0.76 & 0.47 & 1.00 & 0.53 & 0.44 & 0.57 & 0.64 \\
\hline DUSP4 & -0.48 & -0.46 & -0.39 & -0.49 & -0.19 & -0.64 & -0.36 & -0.04 & -0.55 & -0.50 & -0.46 & -0.54 & -0.40 & 0.58 & 0.72 & 0.53 & 1.00 & 0.58 & 0.78 & 0.67 \\
\hline CAPN14 & -0.58 & -0.56 & -0.43 & -0.63 & -0.49 & -0.41 & -0.38 & -0.43 & -0.45 & -0.25 & -0.27 & -0.24 & -0.15 & 0.39 & 0.78 & 0.44 & 0.58 & 1.00 & 0.63 & 0.77 \\
\hline GABRP & $-0.62 \mid$ & -0.58 & -0.54 & -0.59 & -0.34 & -0.58 & -0.45 & -0.14 & -0.70 & $|-0.65|$ & -0.60 & $-0.60 \mid$ & -0.55 & 0.66 & 0.64 & 0.57 & 0.78 & 0.63 & 1.00 & 0.64 \\
\hline STS & -0.66 & -0.64 & -0.60 & -0.72 & -0.51 & -0.49 & -0.54 & -0.53 & -0.44 & -0.17 & -0.14 & -0.14 & -0.02 & 0.47 & 0.81 & $|0.64|$ & 0.67 & 0.77 & 0.64 & 1.00 \\
\hline
\end{tabular}

Figure 4. Graphical Spearman correlation matrix of selected ectocervical genes differentially expressed in the DMPA users. Spearman correlation $r$ values were determined using GraphPad Prism 7. Colors are added for better visualization. See Supplemental Figure 2 for significance of Spearman correlation.

of mononuclear leukocytes" $(Z$ score $=-2.431, n=7)$, "chemotaxis of mononuclear leukocytes" ( $Z$ score $=-2, n=4)$, and "T cell development" $(Z$ score $=-2.187, n=8)$. Importantly, IPA upstream regulator analysis recognized $\beta$-estradiol as the most statistically significant transcriptional regulator in DMPA users, which was predicted to be negatively associated with DMPA use $(P=1.66 \times$ $\left.10^{-24} ; Z=-0.842\right)$, thus underscoring the negative impact of DMPA on the estrogen level/activity in the genital mucosa. Interestingly, the second most significant regulator was tretinoin (all-trans RA; $\left.P=7.65 \times 10^{-18}\right)$, which was predicted to be activated in the ectocervix of DMPA users $(Z=+2.15)$.

In addition to the analyses based on the expression of individual DEGs, we performed analysis of gene set overrepresentation using Biometric Research Branch (BRB) array tools, which revealed that, as defined by gene ontology (GO) categories, the top 7 gene sets enriched in the ectocervical mucosa of DMPA users (comprising about 170 genes) were related to epidermal/epithelial structure, function, and development (Table 3 and Supplemental Table 9). None of these GO categories was enriched in the COC group (Table 3). This result was consistent with significant enrichment of "dermatological diseases and conditions" biofunction associated with the DMPA- but not COC-altered genes.

DMPA effect on cervicovaginal mucosa showed interindividual variability. Unsupervised clustering analysis of DEGs demonstrated that while samples before and after use of DMPA displayed good segregation, there was apparent heterogeneity in gene expression among women within the DMPA group (Figure 2). We were interested to estimate the scale of variations related to the epithelial integrity, and for this purpose designated 3 major groups (G1, G2, G3) defined by cluster analysis based on a gene set of 22 most significantly altered genes with $[\mathrm{FC}]>2$ at $P<0.001$ (Figure 6). Four DMPA samples, which clustered with 2 baseline samples, 


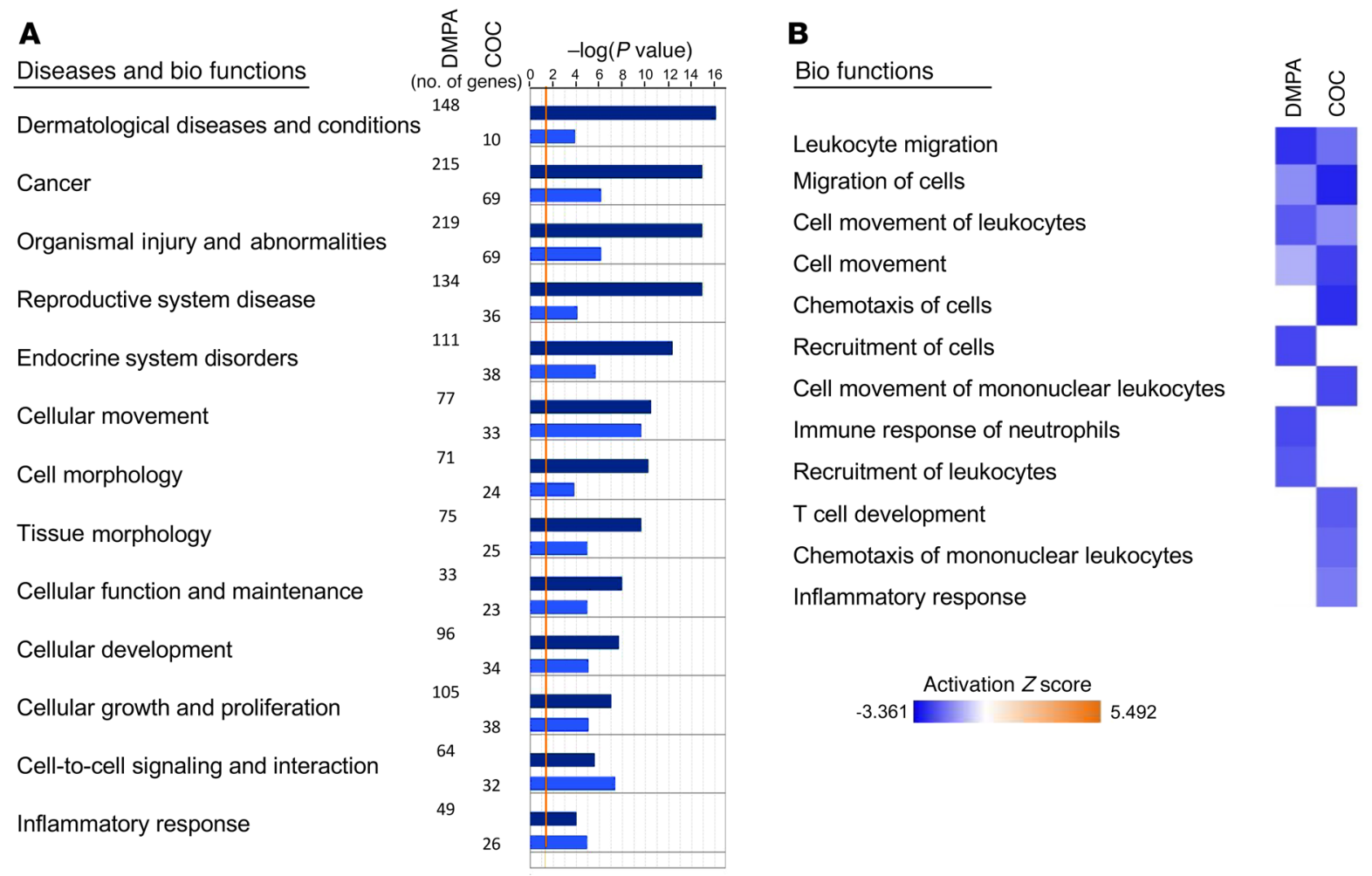

Figure 5. Functional analysis of genes differentially expressed in the ectocervical epithelium of HC users conducted using IPA. (A) Top biological processes most significantly associated with the DEGs. (B) Activation state of biological functions in the ectocervical epithelium in HC users as characterized and sorted by $Z$ scores. The overwhelming majority of computable functions was predicted to be suppressed (negative $Z$ scores). Shown are the top computable biological functions.

were defined as group G1. The majority of DMPA samples $(n=19)$ formed a big cluster that we annotated as group G2, while 5 DMPA samples formed a very distinct cluster defined as group G3. We excluded from the group analysis 3 DMPA samples that were intermixed within the cluster of 29 baseline samples. Transcriptomic analysis revealed that there were 213,404 , and 750 DEGs in G1, G2, and G3, respectively (Figure 7 and Supplemental Tables 10-12).

We created a list of 49 genes based on their relation to the epithelial integrity and significance of their expression changes and estimated transcriptome changes in each group compared with baseline. In group G1, expression of only 6 genes from the list was found altered, and the magnitude of changes for 4 of these genes, PGR, PRSS23, WISP2, and VCAN, was bigger in this group compared with the rest of participants (Supplemental Tables 10 and 13 and Figure 7). Interestingly, there were no changes in expression of these genes in G3, and they displayed strong mutual correlation in their expression, presenting a stand-alone group in the correlation analysis (Figure 4 and Supplemental Figure 3). In the G2 group, expression levels of DEGs were close to those obtained for the whole DMPA group (Supplemental Tables 11 and 13), though some intragroup variability was evident (Figure 6). The most drastic changes were displayed in the G3 group represented by 5 participants. The changes were manifested in dramatically stronger transcriptional changes of epithelial barrier genes, including RPTN $(\mathrm{FC}=-25.1), D S G 1(\mathrm{FC}=-30.2), \operatorname{LCE} 3 \mathrm{D}(\mathrm{FC}=-24.8)$, DMKN $(\mathrm{FC}=$ -10.2), FLG (FC = -9.9), and KRT10 (FC = -4.2) (Figure 7 and Supplemental Tables 12 and 13). Immunohistochemical analysis of pro- teins KRT10 and DSG1 in 26 vaginal specimens taken at baseline $(n=10)$ and after use of DMPA $(n=16)$ indicated that group-related variations in patterns of their expression were in correspondence with those of ectocervical genes (Supplemental Figure 5). Notably, there was also stronger downregulation of GYS2 (FC =-13.0) in G3. Furthermore, in striking contrast to responses in groups G1 and G2, molecular functions associated with immune cell movement categories were found to be activated in the G3 group (Figure 8). Significantly upregulated genes included the leukocyte-attracting chemokines CXCL6, CXCL1, IL8, CCL19, CXCL13, and CCL2, and complement component 3 (C3), also involved in attraction of immune cells (Supplemental Tables 12 and 13).

We compared demographic characteristics of women in these groups and found that women in the least affected group, G1, were significantly younger than women in G2 and G3 (24.3 \pm 5.4 vs. $34.7 \pm 7.1$ years old, $P=0.016$ ), whereas women of the highresponse G3 group tended to have lower BMI compared with G1 and G2 participants ( $26.7 \pm 5.9$ vs. $33.5 \pm 8.2)$, although this difference did not reach significance $(P=0.067)$ (Supplemental Table 14). Although the sample size is small, these data suggest that the effect of DMPA on epithelial integrity might be impacted by the woman's age and weight.

\section{Discussion}

The goal of this study was to gain insight into mechanisms underlying the possible link between use of progestin-only injectable DMPA and risk of HIV-1 acquisition, exploring whole-genome 
Table 3. Top significant gene sets enriched in the ectocervical mucosa after HC use ${ }^{A}$

\begin{tabular}{|c|c|c|c|c|c|}
\hline GO category & GO ontology & CO term & No. of genes & LS permutation $P$ value & KS permutation $P$ value \\
\hline \multicolumn{6}{|l|}{ DMPA } \\
\hline G0:0005578 & CC & Proteinaceous extracellular matrix & 100 & 0.00002 & 0.00001 \\
\hline G0:0043588 & $\mathrm{BP}$ & Skin development & 70 & 0.00003 & 0.00576 \\
\hline G0:0030216 & $\mathrm{BP}$ & Keratinocyte differentiation & 24 & 0.00015 & 0.01159 \\
\hline G0:0009913 & $\mathrm{BP}$ & Epidermal cell differentiation & 29 & 0.00036 & 0.03658 \\
\hline G0:0042445 & $\mathrm{BP}$ & Hormone metabolic process & 33 & 0.0017 & 0.00234 \\
\hline G0:0007565 & $\mathrm{BP}$ & Female pregnancy & 42 & 0.0027 & 0.00146 \\
\hline \multicolumn{6}{|l|}{$\operatorname{COC}$} \\
\hline G0:0007006 & $\mathrm{BP}$ & Mitochondrial membrane organization & 5 & 0.00323 & 0.01135 \\
\hline CO:0001959 & $\mathrm{BP}$ & Regulation of cytokine-mediated signaling pathway & 13 & 0.00031 & 0.00225 \\
\hline G0:0060759 & $\mathrm{BP}$ & Regulation of response to cytokine stimulus & 13 & 0.00031 & 0.00225 \\
\hline G0:0070838 & $\mathrm{BP}$ & Divalent metal ion transport & 38 & 0.00112 & 0.03853 \\
\hline G0:1901019 & $\mathrm{BP}$ & Regulation of calcium ion transmembrane transporter activity & 6 & 0.00112 & 0.03314 \\
\hline G0:0003073 & $\mathrm{BP}$ & Regulation of systemic arterial blood pressure & 13 & 0.00167 & 0.09502 \\
\hline G0:0001960 & $\mathrm{BP}$ & Negative regulation of cytokine-mediated signaling pathway & 11 & 0.00188 & 0.00726 \\
\hline
\end{tabular}

transcription profiling of ectocervical tissues. In women, cervicovaginal mucosal tissues are the main portal of entry for the virus, and therefore gene and structural changes induced by $\mathrm{HC}$ are critical to such relationship. The major finding of the study is that DMPA use caused significant alterations in expression of genes responsible for cervicovaginal epithelial integrity (Figures 9 and 10 and Supplemental Figure 6). Notably, this effect was not observed in the users of COC, which consisted of a combination of the progestin LNG and the synthetic estrogen ethinyl estradiol.

An intact genital epithelium provides an efficient barrier to HIV penetration, since the risk of HIV-1 transmission following a single sexual exposure is low - the average probability of male-to-female HIV-1 transmission is estimated as 1-2 per 1,000 coital acts $(42,43)$.

Ectocervical and vaginal epithelia are structurally similar selfrenewing stratified squamous tissues consisting of several layers (or strata) of keratinocytes, which undergo a process of a continuous tightly orchestrated differentiation from a proliferative basal cell layer through postmitotic suprabasal layers to the outermost corneal layer (or stratum corneum [SC]), where they are transformed into flattened corneocytes and shed off the epithelial surface (Figure 9 and refs. 44-48). During differentiation, keratinocytes switch their transcriptional and translational patterns and change cell shape, metabolism, and intercellular contacts. Disturbances in epithelial differentiation have been shown to result in impaired barrier function $(39,40,49)$.

We found that expression of several prominent markers of epithelial differentiation was altered after DMPA use. Thus,
KRT10, the known marker of differentiating postmitotic suprabasal keratinocytes, was strongly suppressed along with other suprabasal keratins KRT6B and KRT1, while KRT18 and KRT19, which are characteristically expressed in the basal layer cells (50), were upregulated. Downregulation of other genes predominantly expressed in the suprabasal differentiating layers additionally points to defective epithelial differentiation. They include DSG1, the isoform of a desmosomal cadherin responsible for intercellular adhesion in the suprabasal epithelial layers $(51,52)$; DMKN and $S B S N$, clustered genes encoding proteins secreted by upper suprabasal keratinocytes $(53,54)$; and genes encoding proteins essential for the SC (see below).

Besides DSG1, 2 more genes encoding intercellular junction proteins were found downregulated by DMPA: DSC2, a desmosomal cadherin expressed primarily in the lower epithelial layers, and CDSN, a gene coding for an adhesive protein that is added to the extracellular part of desmosomes as they are converted to the corneodesmosomes during keratinocyte transformation to corneocytes (36). Corneodesmosomes hold the corneocytes together until they reach the uppermost part of the SC, where CDSN together with desmosomal cadherins is degraded by specific KLK peptidases to permit the desquamation process. KLK peptidases are also present below the SC, but their activity in these locations is inhibited by specific antipeptidases including SPINKs and SERPINs (37). DMPA use caused suppression of SPINK6 and SERPINB7, which play central roles in the inhibition of KLK activity. Untimely activation of KLK peptidases due to downregulation 


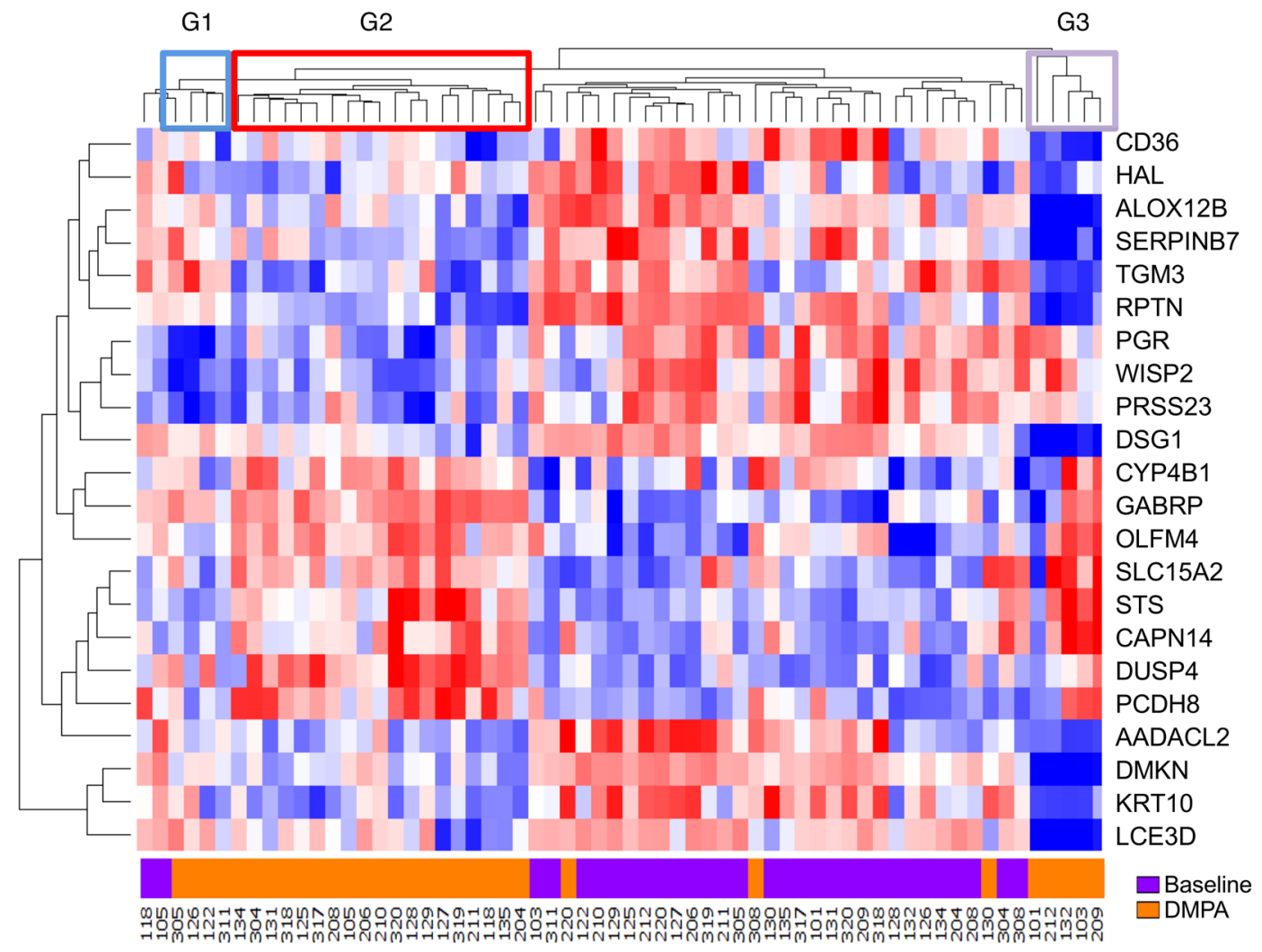

Figure 6. Heatmap of hierarchical clustering based on the genes differentially expressed in the ectocervical epithelium of DMPA users, significant at parametric $\boldsymbol{P}$ value $<\mathbf{0 . 0 0 1}$ and $[\mathrm{FC}] \mathbf{2}$. Boxes on top of the heatmap show groups (G1, G2, G3) designated for analysis of gene expression variability in the DMPA users. of their inhibitors contributes to degradation of DSGs and CDSN $(36,37)$. DSG1 deficiency observed at the protein level might have additionally been due to overexpression of CAPN14, a protease that specifically degrades this cadherin (38). A substantial decline in the desmosomal/corneodesmosomal proteins entails destruction of desmosomes/corneodesmosomes, which are critically important for barrier integrity and epithelial differentiation (refs. 49, 55, and Figure 10).

Transcriptomic analysis revealed DMPA-induced alterations in a number of genes associated with the SC structure. The strongest and most statistically significant was downregulation of RPTN, which belongs to the epidermal differentiation complex (EDC), a $2-\mathrm{Mb}$ region located at chromosomal region 1q21 and comprising about 60 genes, many of them encoding proteins essential for the late steps of keratinocyte differentiation and formation of the SC (56). We also found downregulation of other members of the EDC: $L C E 3 D, L O R, S P R R 2 C$, and, in a group of participants, FLG. In the epidermis, the proteins encoded by these genes are localized to the upper stratum granulosum and SC; however, not much is known about their expression in the cervicovaginal epithelium. In addition to alterations in structural molecules, we observed reduction in expression of genes encoding enzymes essential in the formation of the tight impermeable epidermal barrier in the SC - crosslinking enzyme TGM3 and lipoxygenase ALOX12B (57-59). Notably, these data imply that genes and proteins with well-defined roles in the epidermis are apparently operational in the cervicovaginal mucosa as well. In the epidermis, the SC is considered the principal barrier that prevents penetration of pathogenic molecules and microorganisms, due to a tight cornified envelope (CE) that in association with lipid envelope surrounds the corneocytes embed- ded into extracellular matrix $(49,58,60)$. In the SC of mucosal stratified epithelia, a modified or incomplete version of the CE is thought to be formed, which makes the mucosal SC not as impermeable as the epidermal one (61-65). Nonetheless, virion penetration through the superficial layers of the ectocervical squamous epithelia is relatively infrequent and rather shallow (55). It can, therefore, be suggested that, even if not as efficient as in the skin, the SC of the cervicovaginal epithelium may present the first physical barrier for most microorganisms $(61,62,66)$; downregulation of genes coding for proteins required for proper SC formation may facilitate mucosal penetration of pathogens.

Among other important factors known to undermine epithelial terminal differentiation (both cervicovaginal and epidermal) are vitamin A derivatives. We found that DMPA induced alterations in ectocervical genes encoding metabolic enzymes that control levels of retinoic acid (RA), a principal biologically active form of vitamin A. A gene coding for CYP26B1, an enzyme that irreversibly catabolizes RA, was significantly downregulated, while RDH1O, which mediates the biosynthesis of RA (reviewed in ref. 67), was upregulated. It is conceivable that collective activity of the RA metabolic enzymes in the ectocervical mucosa of DMPA users results in the elevated RA levels, which might have contributed to impairment of mucosal barrier functions (Supplemental Figure 5). This viewpoint is supported by reports that overexpression of RDH10 results in overproduction of RA, which is accompanied by reduced differentiation of keratinocytes (68), while deletion of CYP26B1 leads to aberrant differentiation, defective CE formation, and impairment of barrier function (69).

Vitamin A has long been characterized as an antikeratinizing factor that opposes effects of estrogen $(39,70)$ and is associ- 

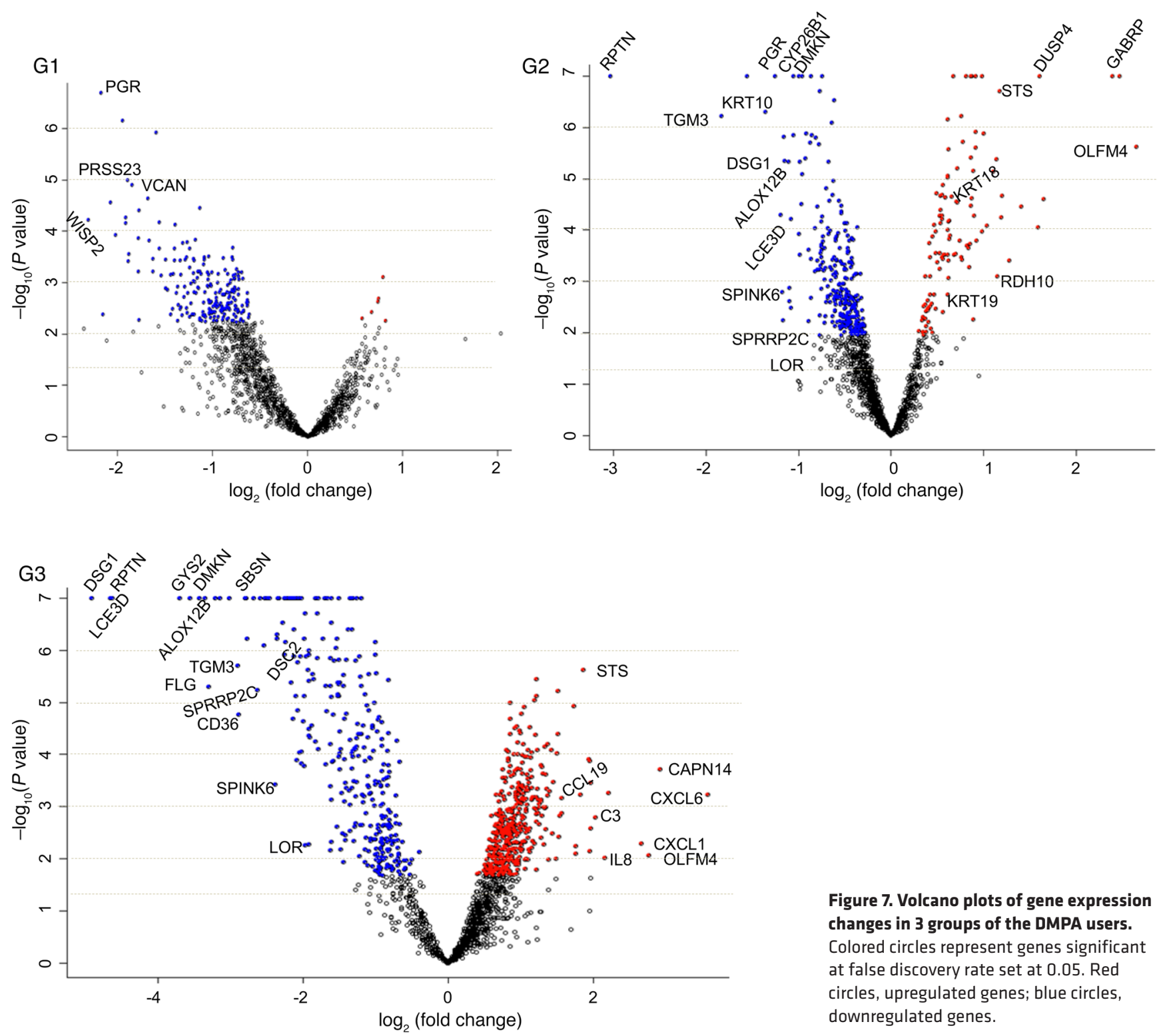

\begin{abstract}
Figure 7. Volcano plots of gene expression changes in $\mathbf{3}$ groups of the DMPA users. Colored circles represent genes significant at false discovery rate set at 0.05 . Red circles, upregulated genes; blue circles, downregulated genes.
\end{abstract}

ated with shedding of desmosomes and dramatic loss of KRT10 (refs. 39, 40, 71, 72, and references therein), and also with decline in other differentiation markers including filaggrin, loricrin, small proline-rich proteins, and transglutaminase (7376), all of which we found downregulated in the cervicovaginal epithelium of the DMPA users.

Interestingly, CYP26B1 was downregulated also in the COC users, in whom changes associated with reduced ectocervical epithelial integrity were not observed. Deficiency in CYP26B1 in these women might be compensated by the estrogenic component present in COC.

Estradiol was identified by IPA upstream regulator analysis as the most statistically significant regulator negatively associated with changes in gene expression in DMPA users, which is in line with the well-established fact that injectable DMPA causes hypoestrogenism with systemic estrogen levels falling into postmenopausal range $(32,77-81)$. Interestingly, many of the genes we found changed in the DMPA users are also altered in postmeno- pausal women, particularly in those experiencing vaginal atrophy, and expression of most of these genes is restored after administration of estrogen (refs. 82, 83, and our unpublished data). The essential role of estrogen in the structural organization and functioning of the cervicovaginal mucosa has long been recognized. Estrogen deficiency, as found in postmenopausal women or women undergoing estrogen suppression therapy, or in ovariectomized animals, is associated with cervicovaginal regression, which can be substantially reversed by exogenous estrogen administration (82-88). Furthermore, in murine models (including humanized ones), DMPA treatment causes suppression of cervicovaginal DSG1 accompanied by increased genital mucosal permeability and enhanced susceptibility to herpes virus type 2 (HSV-2) and HIV-1, which are prevented when mice are concomitantly treated with estrogen $(89,90)$. A role of estrogen in protection against simian immunodeficiency virus (SIV) has been demonstrated in primate models. In ovariectomized macaques, intravaginal inoculation of SIV leads to infection, while SIV transmission is averted 
A

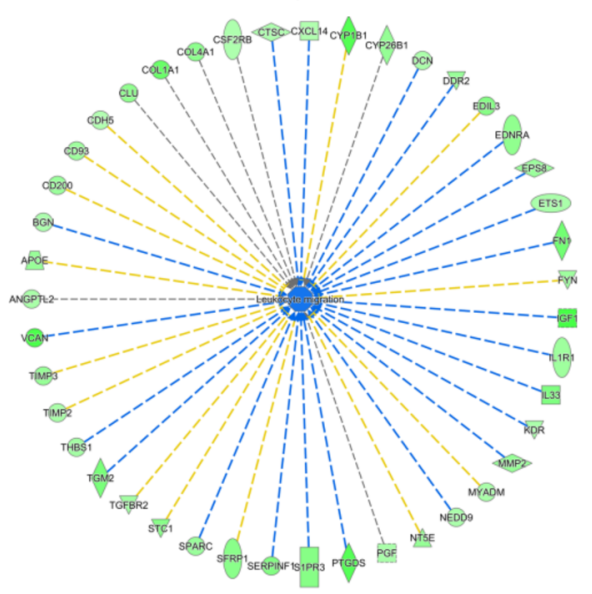

Leukocyte migration $Z=-1.735, P=2.55 \times 10^{-13}, n=43$
G2

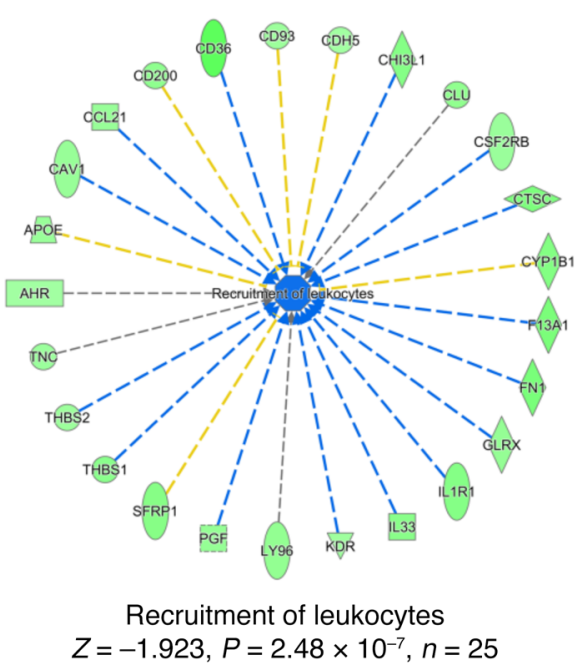

G3

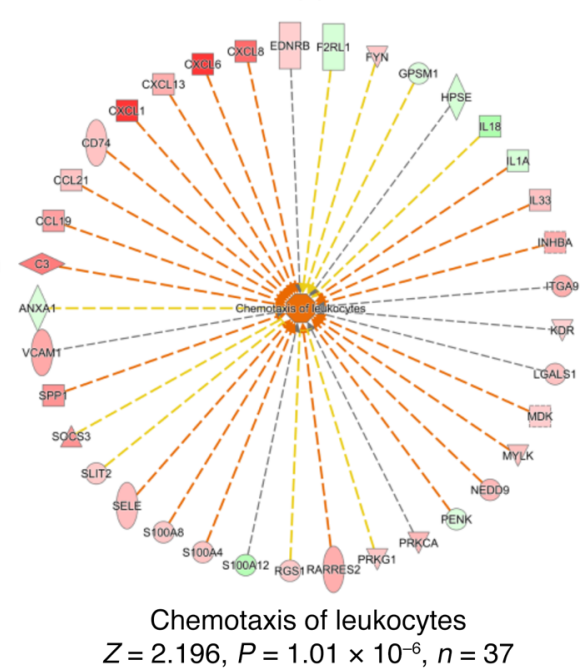

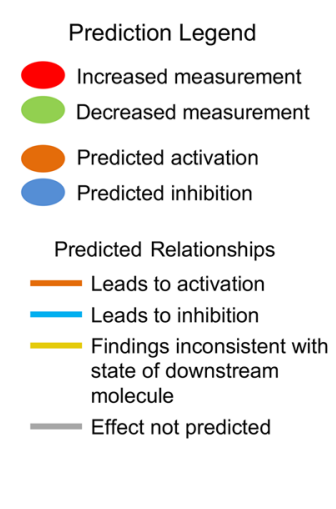

B

\begin{tabular}{l} 
Molecular and cellular function \\
\hline Chemotaxis \\
Recruitment of cells \\
Leukocyte migration \\
Recruitment of leukocytes \\
Cell movement of leukocytes \\
Chemotaxis of leukocytes \\
$\quad$ Activation Zscore \\
$-5.445 \quad 7.710$
\end{tabular}

Figure 8. Activation status of functions related to immune cell migrations in $\mathbf{3}$ groups of the DMPA users (IPA analysis). (A) Networks showing relationships of DEGs with functions. (B) Heatmaps of the activation status of the biological functions in the groups.

when macaques receive systemic or local estrogen $(87,91)$. Estrogen therapy has been shown in these experiments to cause significant cornification and maturation of the epithelium (91).

Ancillary to the structure-related genes, we found reduced expression of GYS2 in the DMPA users, which likely entails a drop in epithelial production of glycogen (92), a nutrient essential for vaginal colonization by Lactobacillus spp. (93). Downregulation of GYS2 points to a mechanism that may underlie the decrease in vaginal colonization by lactobacilli reported for DMPA users (32, 33). Importantly, reduced vaginal abundance of lactobacilli has been linked to impairment of the cervicovaginal epithelial integrity $(94,95)$ and increased susceptibility to sexually transmitted infections including HIV-1 (93, 96-100). Notably, glycogendependent glucose metabolism and vaginal colonization by lactobacilli are stimulated by estrogen (92).

Results presented here together with data published by others suggest that significant and highly correlated DMPA-induced dysregulation of genes responsible for cervicovaginal epithelial integrity was largely a consequence of a DMPA-driven decline in estrogen levels. Substantial impairment of the mucosal protective barrier presents a mechanism contributing to the potential link between increased HIV acquisition rates and DMPA use (Figures 9 and 10). Causal relationship between hypoestrogenism and increased HIV transmission in DMPA users has earlier been proposed $(13,32)$ and discussed in detail $(14)$.

Effects of estrogen and progesterone/progestin are mediated through their cognate receptors - estrogen receptors (ERs) and progesterone receptors (PRs), respectively. There is a significant crosstalk between PRs and ERs. While estrogen bound to ERs is the major factor that positively regulates PR levels in a tissueand cell-specific manner (101-104), downregulation of PRs may be induced by activated RA receptors and progestins themselves $(105,106)$. Our data indicate that use of either progestin-only DMPA or progestin LNG combined with estrogen in COC caused a decrease in ectocervical expression of $P G R$. The observed suppression of PGR in both DMPA and COC users might occur by action of the progestins with an additional contribution from RA, whose level could be elevated due to decreased levels of the retinoid catabolic enzyme CYP26B1. Interestingly, no correlation was detected between expression of $P G R$ and barrier genes, while there was a strong correlation between expression of PGR and CYP26B1. Less significant alterations in these genes in $\mathrm{COC}$ users were likely due to an opposing effect of the estrogen component in COC and/ or possibly because of differential targeting of steroid hormone receptors by the different progestin constituents of both contraceptives. While both MPA and LNG have comparable affinities 


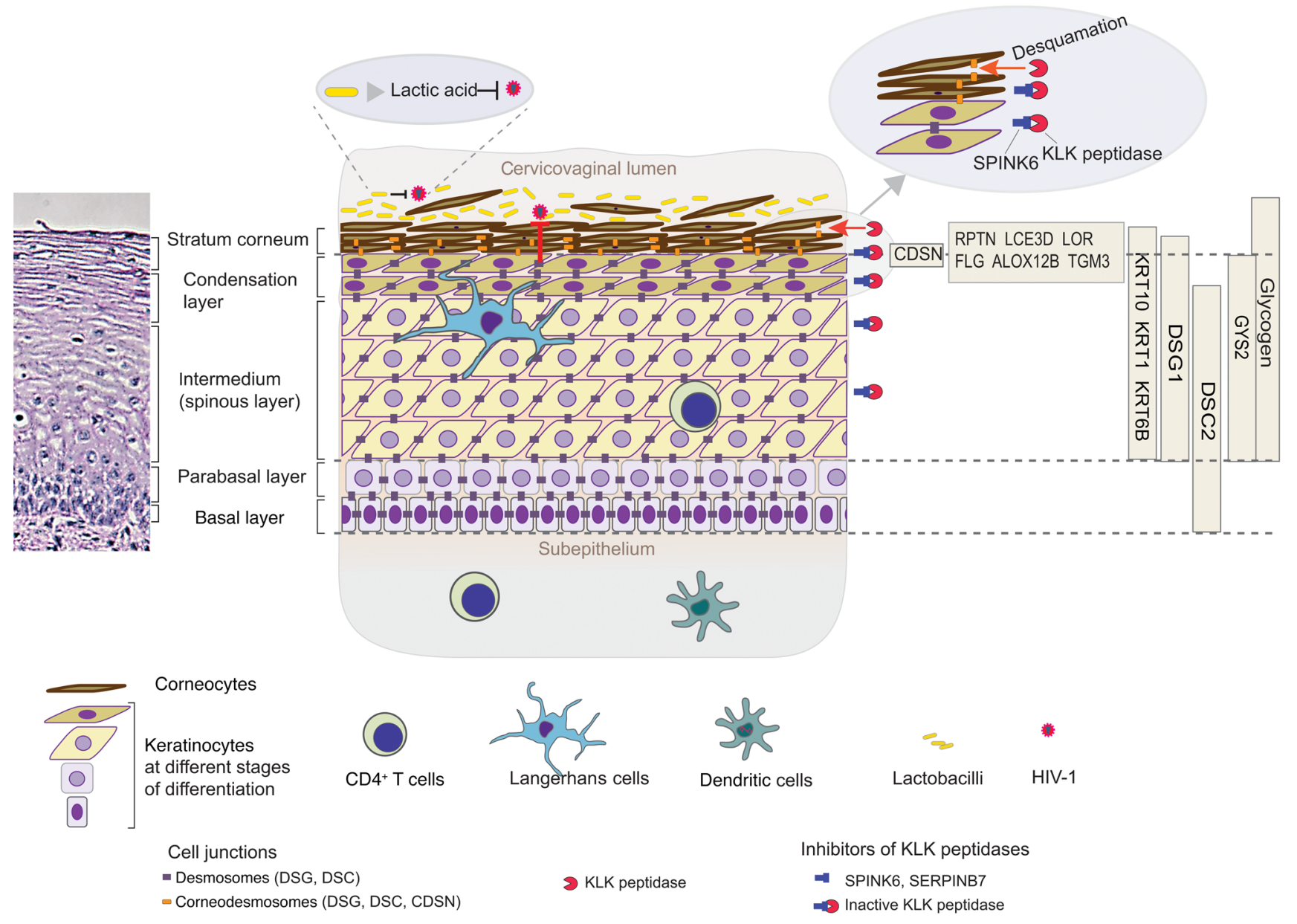

Figure 9. Intact cervicovaginal epithelium. Healthy cervicovaginal epithelium presents an effective barrier against HIV-1 transmission. The epithelium consists of several layers of continuously differentiating keratinocytes interconnected by cell junctional structures. The outermost epithelial layer, the stratum corneum (SC), is the first physical barrier for most microorganisms. Proteins such as RPTN, FLG, LCE3D, LOR, TCM3, and ALOX12B are essential in maintaining the SC. Corneocytes form the SC and are joined by corneodesmosomes, cell junctional structures whose intercellular part consists of DSC, DSC, and CDSN, proteins that are degraded by KLK peptidases in the uppermost part of the SC to promote cell separation and shedding. The multiple keratinocyte layers beneath the SC present the next level of physical protection due to strong cytoskeleton supported by KRTs and cell junctional structures, largely desmosomes, the transmembrane part of which is formed by DSGs and DSCs. Activities of KLK peptidases beneath the SC are suppressed by serine protease inhibitors including SPINKs and SERPINs. In addition to physical barriers, Lactobacillus spp., which are most often the dominant types of bacteria in healthy vaginal lumen, produce lactic acid - a factor that is involved in direct anti-HIV-1 activity. Vaginal colonization and lactic acid production by lactobacilli depend on available glycogen synthesized by keratinocyte GYS2. The expression pattern of epithelial barrier-related proteins, encoded by genes differentially expressed in DMPA users, is shown on the right. Only potential HIV-1 target immune cells are shown for simplicity.

for PRs, MPA additionally binds with high affinity and activates another member of the superfamily of nuclear receptors, glucocorticoid receptor (GR), known as a potent suppressor of proinflammatory mediators (107-110). Activated by MPA, GR has been demonstrated in vitro and ex vivo to downregulate production of key cytokines/chemokines responsible for regulation of immune response in various types of cells, thus contributing to suppression of systemic and local immune protection $(26,109,111,112)$. Compromised immune function is suggested as one of the mechanisms underlying the potential link between HIV-1 acquisition risk and DMPA use (reviewed in refs. 12-14, 16).

While ectocervical transcriptome data do not reflect an assessment of the systemic immune status, our functional analysis of altered genes revealed that in the majority of women participating in our study, biological processes associated with immune cell movement and functions were predicted to be significantly suppressed by use of DMPA, which is consistent with an immunosuppressive role of GR activation and supports observations in other studies. Contrastingly, in a small group of women $(n=5)$, DMPA use caused significant activation of pathways related to immune responses, including immune cell attraction and migration, potentially augmenting susceptibility to HIV-1 acquisition. In this group, we observed significant upregulation of genes encoding chemokines attracting immune cells postulated to be HIV targets, including CCL19 and CCL21, which are ligands for CCR7 receptor expressed by central memory $\mathrm{T}$ cells and dendritic cells (DCs), and CXCL13, which binds CXCR3 expressed on activated $\mathrm{T}$ cells and plasmacytoid DCs. Furthermore, strongly upregulated in this group, CXCL1, CXCL6, and IL 8 genes encode proinflammatory chemokines binding CXCR1 and CXCR2 receptors largely 
A

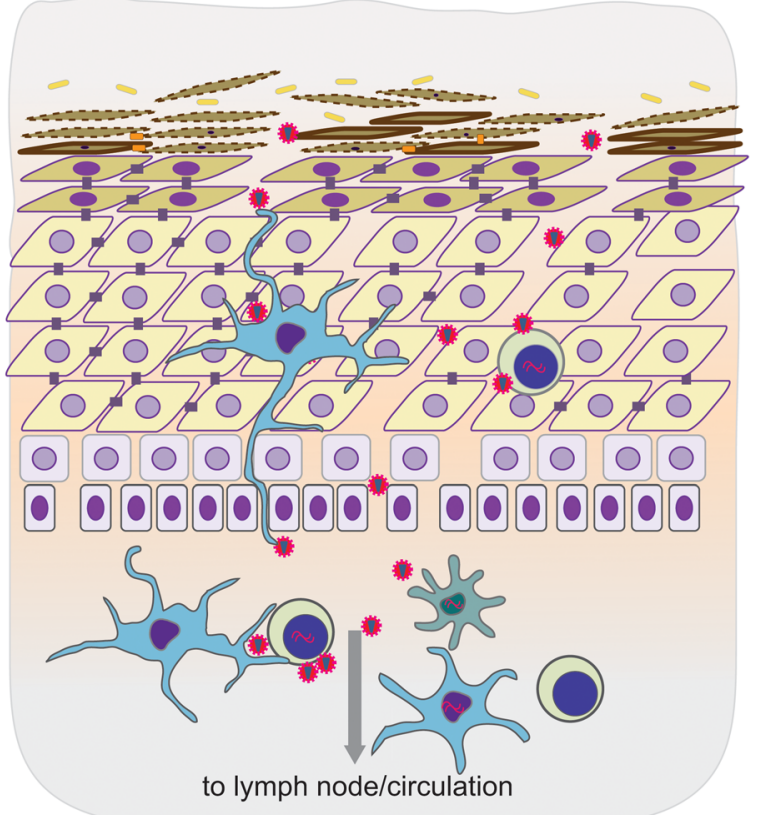

Peptidases

SLK peptidase

OCAPN14 $\approx$ HIV-1 infection

-Chemokines/cytokines
B

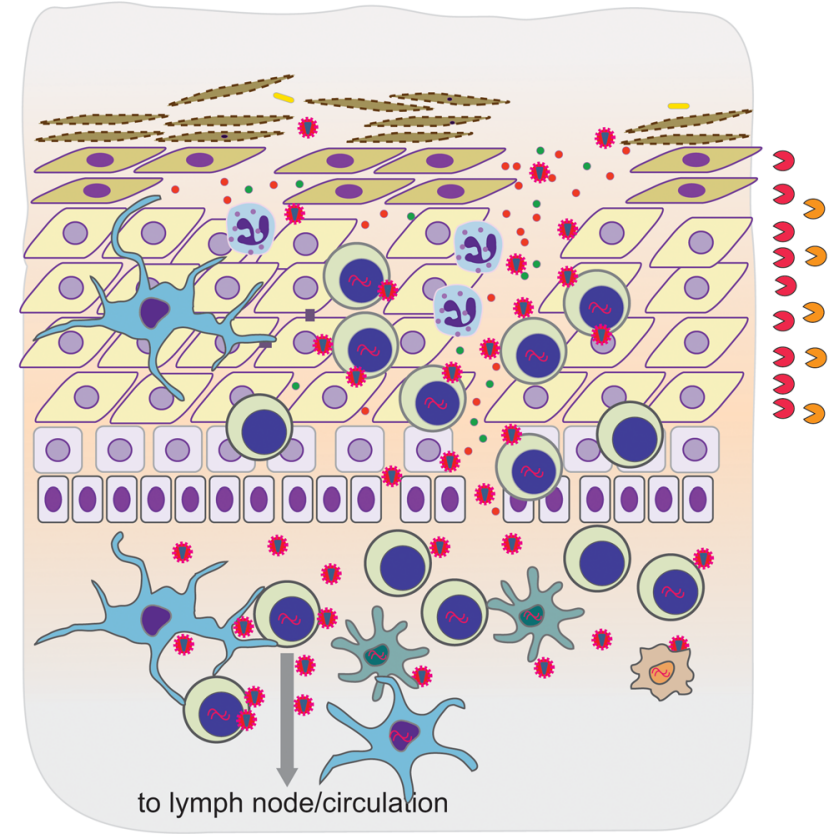

Neutrophils

Macrophages

Figure 10. Model of cervicovaginal mucosal changes in DMPA users plausibly linked to an enhanced HIV-1 susceptibility. Use of DMPA results in altered expression of many genes involved in barrier functions of cervicovaginal mucosa. (A) Decrease in markers of differentiating keratinocytes (such as KRT10, KRT1, KRT6B) indicates a compromised epithelial differentiation. Downregulation of the molecules involved in the SC organization (FLG, RPTN, LCE3D, ALOX12B, TCM3, LOR, and CDSN) and cell junctional proteins in all layers (DSG1 and DSC2) leads to breaches in the epithelial barrier, which is exacerbated by an untimely activation of KLK peptidases due to a decreased production of peptidase inhibitors (specifically SPINK6 and SERPINB7). Decrease in GYS2 expression implicates a drop in the glycogen level and, therefore, lower abundance of Lactobacillus spp. (B) In more expanded responses, molecular changes in the cervicovaginal epithelium are intensified: alterations in the barrier-supporting genes dramatically increase in magnitude, which results in more spacious epithelial breaches and production and release of proinflammatory chemokines that attract more HIV target cells (such as CD4 ${ }^{+} \mathrm{T}$ cells, dendritic cells, macrophages) and damage-related neutrophils. In A and, on a larger scale, in B, the cervicovaginal epithelium of the DMPA users is characterized by loss of epithelial integrity, which allows HIV virions to penetrate and/or transverse the epithelium and reach HIV- 1 target cells for productive infection or be transferred to the draining lymph node or circulating blood. See the legend to Figure 9 for more details.

expressed by neutrophils, which are often linked to tissue damage $(66,113,114)$. Activation of chemokine genes took place concomitantly (and might have been mutually interrelated) with dramatically increased alterations in expression of epithelial barrier genes. Moreover, in this group of women we observed considerably stronger downregulation of GYS2, which might result in an adverse effect on the vaginal microbiota that may in turn further contribute to attenuation of the mucosal protective function (115). It is not clear what mechanism(s) may underlie these stark transcriptome variations. We did not detect significant differences in the baseline characteristics (including gene expression) between this "highresponse" group and the rest of the participants, although we found that women in this group tended to have lower BMI.

One of the limitations of this study was that we did not test women for urogenital infections after 6-week use of HC; therefore, a possible role of newly acquired infections in the observed differential responses could not be ruled out. It may be speculated that factors aggravating DMPA effect could be associated with dynamic alterations in mucosal environment due to, for example, sexual activity and/or intravaginal practices. Exposure to semen induces vaginal immune responses (116-118); besides, vaginal intercourse is frequently accompanied by epithelial mechanical microabrasions (119). Disruption of mucosal integrity resulting from some intravaginal practices $(120,121)$ may be exacerbated by DMPA use (18). We did not assess condom use and frequency of sexual encounters, which is another limitation of the study. In general, variations in the cervicovaginal mucosal microenvironment, including those reported to exist in different populations, might contribute to divergent responses to DMPA administration demonstrated in previous studies, especially taking into account that participants in those studies may represent diverse populations with intrinsically different cervicovaginal environments $(24,115,122-125)$.

Another weakness of this study is that microarray-based results were only partially validated by quantitative reverse transcriptase PCR and immunohistochemical analysis.

In summary, by applying whole-genome transcriptomic analysis to ectocervical biopsies taken before and after use of $\mathrm{HC}$, we found that use of DMPA, but not COC, caused significant alterations in expression of genes responsible for mucosal barrier functions, most likely as a result of DMPA-induced hypoestrogenism. 
We propose that impairment of cervicovaginal epithelial integrity in response to DMPA administration is an important mechanism underlying the potential link between increased risk of HIV-1 acquisition and DMPA use. Our data also indicate that whereas in the majority of the DMPA users in our study biological processes associated with immune cell movement and functions were suppressed, in a small group of women some of these functions were substantially activated, resulting in an inflammatorylike response. In addition to epithelial barrier compromise, both immunosuppression and inflammatory responses could contribute to enhanced HIV transmission.

\section{Methods}

Supplemental Methods are available online with this article; https:// doi.org/10.1172/JCI120583DS1.

Study design. This research was a part of the prospective parallel cohort CONRAD A10-114 study (ClinicalTrials.gov NCT01421368) conducted at 3 clinical sites - Eastern Virginia Medical School, the University of Pittsburgh, and Profamilia, Santo Domingo, Dominican Republic - designed to assess the effect of contraceptive methods on (a) the pharmacokinetics, pharmacodynamics, and safety of topical tenofovir (vaginal gel), and (b) cervicovaginal mucosal parameters associated with HIV infection. A total of 74 healthy women were enrolled (Figure 1). Participants had to report at least 3 months of regular menstrual cycles, of 25-35 days' duration. Participants had not used any $\mathrm{HC}$ in the last 30 days, and had not had DMPA injection in the last 6 months. Exclusion criteria also included positive test for HIV, Trichomonas vaginalis, Neisseria gonorrhoeae, Chlamydia trachomatis, yeast vaginitis, or bacterial vaginosis (BV). We used PCR tests for T.vaginalis, N.gonorrhoeae, and C.trachomatis (Aptima Gen Probe, Hologic), light microscopy to test for yeast vaginitis, and a Gram stain for Nugent score test for BV. Full screening was not repeated after 6 weeks of HC use, but we did do an exam to rule out symptomatic BV or yeast vaginitis. This substudy was not randomized and included 63 healthy women, of median age 32 years (range, 19-49). Thirtyone women chose to receive an injection of DMPA (150 mg; DepoProvera, Pfizer Inc.); 32 women received combined oral contraception (LNG $150 \mu \mathrm{g}$, ethinyl estradiol $30 \mu \mathrm{g}$; Levora, Mayne Pharma) for daily use. The ectocervical and vaginal biopsies were collected as described earlier (126) at cycle days 18 to 26, baseline sampling, and after 6 weeks of $\mathrm{HC}$ use. Ectocervical tissues were placed in RNAlater (Ambion AM7021, Ambion Life Sciences) and kept frozen at $-80^{\circ} \mathrm{C}$ until use. A total of 126 ectocervical specimens were used for gene expression analysis, while only 36 randomly chosen vaginal samples (5 at baseline and 10 after COC use and 10 at baseline and 16 after DMPA use) were available for immunohistochemical (IHC) analysis in this substudy, because samples for IHC analysis were designated and extensively used for the analysis of effects of HC on pharmacokinetics, pharmacodynamics, and safety of tenofovir. Vaginal tissues assigned for IHC protein detection were placed into 10\% neutral formalin for 24-48 hours, and processed as described below.

RNA isolation. To isolate RNA, ectocervical tissues were placed into Trizol (Invitrogen Life Technologies) and homogenized using an OMNI international homogenizer. Total RNA was extracted and then purified using RNeasy Mini Kit columns (Qiagen) according to the manufacturer's instructions. The integrity of RNA was qualified by Agilent Bioanalyzer 2100 capillary electrophoresis, and purity and quantity were determined using a Nanodrop ND-1000 spectrophotometer. A report on RNA quality control is presented in Supplemental Table 15.

Microarray gene expression analysis, data normalization, and statistical analysis. Gene expression analysis was conducted as previously described (127) with some modifications. Briefly, microarray expression profiling using Affymetrix U133 Plus 2 arrays was performed by Asuragen Inc. Affymetrix raw data (.CEL files) were processed and analyzed using Biometric Research Branch (BRB) Arrays Tool version 4.5.1 developed by Simon and Lam (National Cancer Institute; available at http://linus.nci.nih.gov/BRB-ArrayTools.html). We identified genes that were differentially expressed between classes by using a multivariate permutation test set to provide $80 \%$ confidence that the false discovery rate was less than $5 \%$. Genes that passed these criteria were considered differentially expressed (DEGs). In these settings, DEGs' fold change difference between the studied groups was greater than 1.2. The microarray data are available through the Gene Expression Omnibus with accession number GSE110313.

Hierarchical clustering analysis of DEGs was performed using unsupervised average linkage with Euclidean distance metric.

Gene set comparison. Gene set comparison was conducted using $\mathrm{BRB}$ array tools as described in the Simon and Lam BRB array tool user guide (http://linus.nci.nih.gov/brb). Annotated gene sets were defined based on gene ontology (GO) categories. Analysis of GO groups rather than individual genes enables data on biologically related genes to reinforce each other without relying on gene selection. Tests used to find significant gene sets were the Fisher (LS) statistic and the Kolmogorov-Smirnov (KS) statistic. The threshold of determining significant gene sets was 0.005. LS/KS permutation test finds gene sets that have more genes differentially expressed among the phenotype classes than expected by chance.

Functional analysis of significant genes. Biofunctions and molecular and cellular processes that are significantly associated with DEGs in our data sets were determined using Ingenuity Pathway Analysis (IPA) software. Significance is expressed as $P$ value calculated by righttailed Fisher's exact test, which measures the likelihood that the association between DEGs from our data set and a given process/function is due to random chance.

IPA's Upstream Regulator Analysis tool, which uses the IPA knowledge base, was explored to predict upstream regulators that can affect expression of genes from the analyzed data sets.

Immunohistochemistry. IHC analysis was performed on paraffinembedded vaginal biopsies as described earlier (23). Briefly, tissue sections $(5 \mu \mathrm{m})$ were deparaffinized and rehydrated followed by antigen retrieval in citrate buffer ( $\mathrm{pH} 6.2$; DAKO) at $98^{\circ} \mathrm{C}$. The tissue sections were incubated with primary antibodies overnight at $4^{\circ} \mathrm{C}$, followed by treatment with appropriate biotinylated secondary antibodies for 1 hour at room temperature. Details on antibodies and their working dilutions are presented in Supplemental Table 16. The sections were treated with $\mathrm{ABC}$ reagent (Vector Laboratories), and staining reaction was developed using an AEC chromogen substrate kit (SkyTek Labs).

Statistics. GraphPad Prism software (version 7.01) was used to assess association between expression of DEGs using Spearman's correlation coefficients. Details of statistical analyses of microarray data, gene set comparison, and functional analysis of DEGs are given in the corresponding sections above. For the demographic data, statistical analyses were performed with SAS version 9.3. We compared 
continuous endpoints from COC and DMPA cohorts using an independent-samples 2-tailed Student's $t$ test for normally distributed data or Wilcoxon-Mann-Whitney test for non-normally distributed data. For categorical variables, we used $\chi^{2}$ statistic or Fisher's exact tests as indicated by expected cell size. Statistical significance was determined at $\alpha=0.05$.

Study approval. The study was approved by the institutional review boards of Eastern Virginia Medical School, the University of Pittsburgh, and Profamilia, Santo Domingo, Dominican Republic. Signed informed consent was received from all participants prior to their inclusion in the study.

\section{Author contributions}

GFD, JLS, CKM, and ART designed and conducted the clinical study. NC, NY, SSJ, and IAZ performed sample analysis. IAZ, XF, and OEA analyzed and interpreted data. IAZ performed visualiza- tion and data presentation. SMA was the project administrator. IAZ and GFD wrote the manuscript. SMA, NY, and ART provided editorial comments and critique.

\section{Acknowledgments}

This study was supported by the United States Agency for International Development (USAID) under Cooperative Agreement GPO-A-00-08-00005-00. The contents are the sole responsibility of the authors and do not necessarily reflect the views of their institutions, USAID, or the United States Government.

Address correspondence to: Irina A. Zalenskaya or Gustavo F. Doncel, CONRAD, Eastern Virginia Medical School 601 Colley Avenue, Norfolk, Virginia 23507, USA. Phone: 757.446.7271; Email: ZalensIA@EVMS.edu (I.A. Zalenskaya). Phone: 703.276.4020; Email: DoncelGF@EVMS.edu (G.F. Doncel).
1. Plummer FA, et al. Cofactors in male-female sexual transmission of human immunodeficiency virus type 1. J Infect Dis. 1991;163(2):233-239.

2. Rehle T, Brinkmann UK, Siraprapasiri T, Coplan $\mathrm{P}$, Aiemsukawat C, Ungchusak K. Risk factors of HIV-1 infection among female prostitutes in Khon Kaen, Northeast Thailand. Infection. 1992;20(6):328-331.

3. Polis CB, et al. An updated systematic review of epidemiological evidence on hormonal contraceptive methods and HIV acquisition in women. AIDS. 2016;30(17):2665-2683.

4. Polis CB, et al. Hormonal contraceptive methods and risk of HIV acquisition in women: a systematic review of epidemiological evidence. Contraception. 2014;90(4):360-390.

5. Ralph LJ, McCoy SI, Shiu K, Padian NS. Hormonal contraceptive use and women's risk of HIV acquisition: a meta-analysis of observational studies. Lancet Infect Dis. 2015;15(2):181-189.

6. Morrison CS, et al. Hormonal contraception and the risk of HIV acquisition: an individual participant data meta-analysis. PLoS Med. 2015;12(1):e1001778.

7. Morrison CS, Turner AN, Jones LB. Highly effective contraception and acquisition of HIV and other sexually transmitted infections. Best Pract Res Clin Obstet Gynaecol. 2009;23(2):263-284.

8. Byrne EH, et al. Association between injectable progestin-only contraceptives and HIV acquisition and HIV target cell frequency in the female genital tract in South African women: a prospective cohort study. Lancet Infect Dis. 2016;16(4):441-448.

9. Heffron R, et al. Use of hormonal contraceptives and risk of HIV-1 transmission: a prospective cohort study. Lancet Infect Dis. 2012;12(1):19-26.

10. Noguchi LM, et al. Risk of HIV-1 acquisition among women who use diff erent types of injectable progestin contraception in South Africa: a prospective cohort study. Lancet HIV. 2015;2(7):e279-e287.

11. Butler AR, Smith JA, Polis CB, Gregson S, Stanton D, Hallett TB. Modelling the global competing risks of a potential interaction between injectable hormonal contraception and HIV risk. AIDS. 2013;27(1):105-113.
12. Achilles SL, Hillier SL. The complexity of contraceptives: understanding their impact on genital immune cells and vaginal microbiota. AIDS. 2013;27(suppl 1):S5-S15.

13. Hel Z, Stringer E, Mestecky J. Sex steroid hormones, hormonal contraception, and the immunobiology of human immunodeficiency virus-1 infection. Endocr Rev. 2010;31(1):79-97.

14. Hickey M, Marino JL, Tachedjian G. Critical review: mechanisms of HIV transmission in depo-provera users: the likely role of hypoestrogenism. J Acquir Immune Defic Syndr. 2016;71(1):1-7.

15. Murphy K, Irvin SC, Herold BC. Research gaps in defining the biological link between HIV risk and hormonal contraception. Am J Reprod Immunol. 2014;72(2):228-235.

16. Hapgood JP. Immunosuppressive biological mechanisms support reassessment of use of the injectable contraceptive medroxyprogesterone acetate. Endocrinology. 2013;154(3):985-988.

17. Hapgood JP, Kaushic C, Hel Z. Hormonal contraception and HIV-1 acquisition: biological mechanisms. Endocr Rev. 2018;39(1):36-78.

18. Birse KD, et al. Genital injury signatures and microbiome alterations associated with depot medroxyprogesterone acetate usage and intravaginal drying practices. J Infect Dis. 2017;215(4):590-598.

19. Deese J, et al. Injectable progestin-only contraception is associated with increased levels of pro-inflammatory cytokines in the female genital tract. Am J Reprod Immunol. 2015;74(4):357-367.

20. Francis SC, et al. Immune activation in the female genital tract: expression profiles of soluble proteins in women at high risk for HIV infection. PLoS One. 2016;11(1):e0143109.

21. Guthrie BL, et al. Depot medroxyprogesterone acetate use is associated with elevated innate immune effector molecules in cervicovaginal secretions of HIV-1-uninfected women. J Acquir Immune Defic Syndr. 2015;69(1):1-10.

22. Morrison C, et al. Cervical inflammation and immunity associated with hormonal contraception, pregnancy, and HIV-1 seroconversion. J Acquir Immune Defic Syndr. 2014;66(2):109-117. 23. Chandra N, et al. Depot medroxyprogester- one acetate increases immune cell numbers and activation markers in human vaginal mucosal tissues. AIDS Res Hum Retroviruses. 2013;29(3):592-601.

24. Ghanem KG, et al. Influence of sex hormones, HIV status, and concomitant sexually transmitted infection on cervicovaginal inflammation. J Infect Dis. 2005;191(3):358-366.

25. Wieser F, Hosmann J, Tschugguel W, Czerwenka K, Sedivy R, Huber JC. Progesterone increases the number of Langerhans cells in human vaginal epithelium. Fertil Steril. 2001;75(6):1234-1235.

26. Huijbregts RP, et al. Hormonal contraception and HIV-1 infection: medroxyprogesterone acetate suppresses innate and adaptive immune mechanisms. Endocrinology. 2013;154(3):1282-1295.

27. Michel KG, Huijbregts RP, Gleason JL, Richter HE, Hel Z. Effect of hormonal contraception on the function of plasmacytoid dendritic cells and distribution of immune cell populations in the female reproductive tract. J Acquir Immune Defic Syndr. 2015;68(5):511-518.

28. Ngcapu S, et al. Lower concentrations of chemotactic cytokines and soluble innate factors in the lower female genital tract associated with the use of injectable hormonal contraceptive. J Reprod Immunol. 2015;110:14-21.

29. Huijbregts RP, Michel KG, Hel Z. Effect of progestins on immunity: medroxyprogesterone but not norethisterone or levonorgestrel suppresses the function of T cells and pDCs. Contraception. 2014;90(2):123-129.

30. Quispe Calla NE, Ghonime MG, Cherpes TL, Vicetti Miguel RD. Medroxyprogesterone acetate impairs human dendritic cell activation and function. Hum Reprod. 2015;30(5):1169-1177.

31. Trunova N, et al. Progestin-based contraceptive suppresses cellular immune responses in SHIV-infected rhesus macaques. Virology. 2006;352(1):169-177.

32. Miller L, Patton DL, Meier A, Thwin SS, Hooton TM, Eschenbach DA. Depomedroxyprogesterone-induced hypoestrogenism and changes in vaginal flora and epithelium. Obstet Gynecol. 2000;96(3):431-439.

33. Mitchell CM, et al. Long-term effect of depot medroxyprogesterone acetate on vaginal micro- 
biota, epithelial thickness and HIV target cells. J Infect Dis. 2014;210(4):651-655.

34. Ferreira VH, et al. Medroxyprogesterone acetate regulates HIV-1 uptake and transcytosis but not replication in primary genital epithelial cells, resulting in enhanced T-cell infection. J Infect Dis. 2015;211(11):1745-1756.

35. Irvin SC, Herold BC. Molecular mechanisms linking high dose medroxyprogesterone with HIV-1 risk. PLoS One. 2015;10(3): 0121135.

36. Ishida-Yamamoto A, Igawa S. The biology and regulation of corneodesmosomes. Cell Tissue Res. 2015;360(3):477-482.

37. Haftek M. Epidermal barrier disorders and corneodesmosome defects. Cell Tissue Res. 2015;360(3):483-490.

38. Davis BP, et al. Eosinophilic esophagitis-linked calpain 14 is an IL-13-induced protease that mediates esophageal epithelial barrier impairment. JCI Insight. 2016;1(4):e86355.

39. Chateau D, Boehm N. Regulation of differentiation and keratin 10 expression by all-trans retinoic acid during the estrous cycle in the rat vaginal epithelium. Cell Tissue Res. 1996;284(3):373-381.

40. Fuchs E, Green H. Regulation of terminal differentiation of cultured human keratinocytes by vitamin A. Cell. 1981;25(3):617-625.

41. Purohit A, Woo LW, Potter BV. Steroid sulfatase: a pivotal player in estrogen synthesis and metabolism. Mol Cell Endocrinol. 2011;340(2):154-160.

42. Gray RH, Wawer MJ. Probability of heterosexual HIV-1 transmission per coital act in sub-Saharan Africa. J Infect Dis. 2012;205(3):351-352.

43. Hughes JP, et al. Determinants of per-coital-act HIV-1 infectivity among African HIV-1-serodiscordant couples. J Infect Dis. 2012;205(3):358-365.

44. Alexandre KB, Mufhandu HT, London GM, Chakauya E, Khati M. Progress and perspectives on HIV-1 microbicide development. Virology. 2016;497:69-80.

45. Forsberg JG. A morphologist's approach to the vagina - age-related changes and estrogen sensitivity. Maturitas. 1995;22(suppl):S7-S15.

46. King BF. Ultrastructure of the nonhuman primate vaginal mucosa: epithelial changes during the menstrual cycle and pregnancy. JUltrastruct Res. 1983;82(1):1-18.

47. Shattock RJ, Moore JP. Inhibiting sexual transmission of HIV-1 infection. Nat Rev Microbiol. 2003;1(1):25-34.

48. Blaskewicz CD, Pudney J, Anderson DJ. Structure and function of intercellular junctions in human cervical and vaginal mucosal epithelia. Biol Reprod. 2011;85(1):97-104.

49. Baroni A, Buommino E, De Gregorio V, Ruocco E, Ruocco V, Wolf R. Structure and function of the epidermis related to barrier properties. Clin Dermatol. 2012;30(3):257-262.

50. Bragulla HH, Homberger DG. Structure and functions of keratin proteins in simple, stratified, keratinized and cornified epithelia. J Anat. 2009;214(4):516-559.

51. Green KJ, Gaudry CA. Are desmosomes more than tethers for intermediate filaments? Nat Rev Mol Cell Biol. 2000;1(3):208-216.

52. Kottke MD, Delva E, Kowalczyk AP. The desmosome: cell science lessons from human diseases. JCell Sci. 2006;119(pt 5):797-806.
53. Matsui T, et al. Identification of novel keratinocyte-secreted peptides dermokine- $\alpha /-\beta$ and a new stratified epithelium-secreted protein gene complex on human chromosome 19q13.1. Genomics. 2004;84(2):384-397.

54. Toulza E, et al. Large-scale identification of human genes implicated in epidermal barrier function. Genome Biol. 2007;8(6):R107.

55. Carias AM, et al. Defining the interaction of HIV-1 with the mucosal barriers of the female reproductive tract. J Virol. 2013;87(21):11388-11400.

56. Henry J, et al. Update on the epidermal differentiation complex. Front Biosci (Landmark Ed). 2012;17:1517-1532.

57. Candi E, Schmidt R, Melino G. The cornified envelope: a model of cell death in the skin. Nat Rev Mol Cell Biol. 2005;6(4):328-340.

58. Elias PM, et al. Formation and functions of the corneocyte lipid envelope (CLE). Biochim Biophys Acta. 2014;1841(3):314-318.

59. Akiyama M. Updated molecular genetics and pathogenesis of ichthiyoses. Nagoya J Med Sci. 2011;73(3-4):79-90.

60. Proksch E, Brandner JM, Jensen JM. The skin: an indispensable barrier. Exp Dermatol. 2008;17(12):1063-1072.

61. Anderson DJ, Marathe J, Pudney J. The structure of the human vaginal stratum corneum and its role in immune defense. Am J Reprod Immunol. 2014;71(6):618-623.

62. King BF. The permeability of nonhuman primate vaginal epithelium: a freeze-fracture and tracer-perfusion study. J Ultrastruct Res. 1983;83(1):99-110.

63. Dawson DV, Drake DR, Hill JR, Brogden KA, Fischer CL, Wertz PW. Organization, barrier function and antimicrobial lipids of the oral mucosa. Int J Cosmet Sci. 2013;35(3):220-223.

64. Presland RB, Jurevic RJ. Making sense of the epithelial barrier: what molecular biology and genetics tell us about the functions of oral mucosal and epidermal tissues. J Dent Educ. 2002;66(4):564-574.

65. Squier CA. The permeability of oral mucosa. Crit Rev Oral Biol Med.1991;2(1):13-32.

66. Burgener A, McGowan I, Klatt NR. HIV and mucosal barrier interactions: consequences for transmission and pathogenesis. Curr Opin Immunol. 2015;36:22-30.

67. Kedishvili NY. Retinoic acid synthesis and degradation. Subcell Biochem. 2016;81:127-161.

68. Lee SA, Belyaeva OV, Wu L, Kedishvili NY. Retinol dehydrogenase 10 but not retinol/ sterol dehydrogenase(s) regulates the expression of retinoic acid-responsive genes in human transgenic skin raft culture. J Biol Chem. 2011;286(15):13550-13560.

69. Okano J, et al. Increased retinoic acid levels through ablation of Cyp26b1 determine the processes of embryonic skin barrier formation and peridermal development. J Cell Sci. 2012; 125(pt 7):1827-1836.

70. Gorodeski GI, Eckert RL, Utian WH, Sheean L, Rorke EA. Retinoids, sex steroids and glucocorticoids regulate ectocervical cell envelope formation but not the level of the envelope precursor, involucrin. Differentiation. 1989;42(2):75-80.

71. Elias PM. Epidermal effects of retinoids: supra- molecular observations and clinical implications. JAm Acad Dermatol. 1986;15(4 pt 2):797-809.

72. Yuspa SH, Harris CC. Altered differentiation of mouse epidermal cells treated with retinyl acetate in vitro. Exp Cell Res. 1974;86(1):95-105.

73. Floyd EE, Jetten AM. Regulation of type I (epidermal) transglutaminase mRNA levels during squamous differentiation: down regulation by retinoids. Mol Cell Biol. 1989;9(11):4846-4851.

74. Hohl D, Lichti U, Breitkreutz D, Steinert PM, Roop DR. Transcription of the human loricrin gene in vitro is induced by calcium and cell density and suppressed by retinoic acid. J Invest Dermatol.1991;96(4):414-418.

75. Holmen SL, Robertson SA, Zylstra CR, Williams BO. Wnt-independent activation of beta-catenin mediated by a Dkk1-Fz5 fusion protein. Biochem Biophys Res Commun. 2005;328(2):533-539.

76. Presland RB, Tomic-Canic M, Lewis SP, Dale BA. Regulation of human profilaggrin promoter activity in cultured epithelial cells by retinoic acid and glucocorticoids. J Dermatol Sci. 2001;27(3):192-205.

77. Bahamondes L, et al. The effect upon the human vaginal histology of the long-term use of the injectable contraceptive Depo-Provera. Contraception. 2000;62(1):23-27.

78. Bahamondes MV, et al. Human vaginal histology in long-term users of the injectable contraceptive depot-medroxyprogesterone acetate. Contraception. 2014;90(2):117-122.

79. Mauck CK, et al. The effect of one injection of Depo-Provera on the human vaginal epithelium and cervical ectopy. Contraception. 1999;60(1):15-24.

80. Jeppsson S, Gershagen S, Johansson ED, Rannevik G. Plasma levels of medroxyprogesterone acetate (MPA), sex-hormone binding globulin, gonadal steroids, gonadotrophins and prolactin in women during long-term use of depo-MPA (Depo-Provera) as a contraceptive agent. Acta Endocrinol. 1982;99(3):339-343.

81. Mishell DR. Pharmacokinetics of depot medroxyprogesterone acetate contraception. J Reprod Med. 1996;41(5 suppl):381-390.

82. Cotreau MM, et al. A study of $17 \beta$-estradiolregulated genes in the vagina of postmenopausal women with vaginal atrophy. Maturitas. 2007;58(4):366-376.

83. Hummelen R, et al. Vaginal microbiome and epithelial gene array in post-menopausal women with moderate to severe dryness. PLoS One. 2011;6(11):e26602.

84. Gimenez-Conti IB, Lynch M, Roop D, Bhowmik S, Majeski P, Conti CJ. Expression of keratins in mouse vaginal epithelium. Differentiation. 1994;56(3):143-151.

85. Barker TE, Walker BE. Initiation of irreversible differentiation in vaginal epithelium. Anat Rec. 1966;154(1):149-159.

86. Lev-Sagie A. Vulvar and vaginal atrophy: physiology, clinical presentation, and treatment considerations. Clin Obstet Gynecol. 2015;58(3):476-491.

87. Smith SM, Baskin GB, Marx PA. Estrogen protects against vaginal transmission of simian immunodeficiency virus. J Infect Dis. 2000;182(3):708-715.

88. Jones RC, Edgren RA. The effects of various steroids on the vaginal histology in the rat. Fertil 
Steril. 1973;24(4):284-291.

89. Quispe Calla NE, et al. Medroxyprogesterone acetate and levonorgestrel increase genital mucosal permeability and enhance susceptibility to genital herpes simplex virus type 2 infection. Mucosal Immunol. 2016;9(6):1571-1583.

90. Quispe Calla NE, Vicetti Miguel RD, Glick ME, Kwiek JJ, Gabriel JM, Cherpes TL. Exogenous oestrogen inhibits genital transmission of cellassociated HIV-1 in DMPA-treated humanized mice. J Int AIDS Soc. 2018;21(1):e25063.

91. Smith SM, et al. Topical estrogen protects against SIV vaginal transmission without evidence of systemic effect. AIDS. 2004;18(12):1637-1643.

92. Linhares IM, Summers PR, Larsen B, Giraldo $\mathrm{PC}$, Witkin SS. Contemporary perspectives on vaginal $\mathrm{pH}$ and lactobacilli. Am JObstet Gynecol. 2011;204(2):120.e1-120.e5.

93. Mirmonsef P, Spear GT. The barrier to HIV transmission provided by genital tract Lactobacillus colonization. Am J Reprod Immunol. 2014;71(6):531-536.

94. Zhong M, et al. L-selectin and P-selectin are novel biomarkers of cervicovaginal inflammation for preclinical mucosal safety assessment of antiHIV-1 microbicide. Antimicrob Agents Chemother. 2012;56(6):3121-3132.

95. Zevin AS, et al. Microbiome composition and function drives wound-healing impairment in the female genital tract. PLoS Pathog. 2016;12(9):e1005889.

96. Gosmann C, et al. Lactobacillus-deficient cervicovaginal bacterial communities are associated with increased HIV acquisition in young South African women. Immunity. 2017;46(1):29-37.

97. Martin HL, et al. Vaginal lactobacilli, microbial flora, and risk of human immunodeficiency virus type 1 and sexually transmitted disease acquisition. J Infect Dis. 1999;180(6):1863-1868.

98. Atashili J, Poole C, Ndumbe PM, Adimora AA, Smith JS. Bacterial vaginosis and HIV acquisition: a meta-analysis of published studies. AIDS. 2008;22(12):1493-1501.

99. Tyssen D, et al. Anti-HIV-1 activity of lactic acid in human cervicovaginal fluid. mSphere. 2018;3(4):e00055-18.

100.Tachedjian G, O'Hanlon DE, Ravel J. The implausible "in vivo" role of hydrogen peroxide as an antimicrobial factor produced by vaginal microbiota. Microbiome. 2018;6(1):29.

101.Jacobsen BM, Horwitz KB. Progesterone receptors, their isoforms and progesterone regulated transcription. Mol Cell Endocrinol. 2012;357(1-2):18-29.

102. Mehta FF, et al. Distinct functions and regulation of epithelial progesterone receptor in the mouse cervix, vagina, and uterus. Oncotarget. 2016;7(14):17455-17467.
103.Thomas C, Gustafsson JÅ. Progesterone receptorestrogen receptor crosstalk: a novel insight. Trends Endocrinol Metab. 2015;26(9):453-454.

104.Katzenellenbogen BS. Mechanisms of action and cross-talk between estrogen receptor and progesterone receptor pathways. J Soc Gynecol Investig. 2000;7(1 suppl):S33-S37.

105. Alexander IE, Clarke CL, Shine J, Sutherland RL. Progestin inhibition of progesterone receptor gene expression in human breast cancer cells. Mol Endocrinol. 1989;3(9):1377-1386.

106. Clarke CL, Graham J, Roman SD, Sutherland RL. Direct transcriptional regulation of the progesterone receptor by retinoic acid diminishes progestin responsiveness in the breast cancer cell line T-47D. J Biol Chem. 1991;266(28):18969-18975.

107. Flammer JR, Rogatsky I. Minireview: Glucocorticoids in autoimmunity: unexpected targets and mechanisms. Mol Endocrinol. 2011;25(7):1075-1086.

108. Govender Y, et al. The injectable-only contraceptive medroxyprogesterone acetate, unlike norethisterone acetate and progesterone, regulates inflammatory genes in endocervical cells via the glucocorticoid receptor. PLoS One. 2014;9(5):e96497.

109. Hapgood JP, Ray RM, Govender Y, Avenant C, Tomasicchio M. Differential glucocorticoid receptor-mediated effects on immunomodulatory gene expression by progestin contraceptives: implications for HIV-1 pathogenesis. Am J Reprod Immunol. 2014;71(6):505-512.

110. Ratman D, et al. How glucocorticoid receptors modulate the activity of other transcription factors: a scope beyond tethering. Mol Cell Endocrinol. 2013;380(1-2):41-54.

111. Africander DJ, Storbeck KH, Hapgood JP. A comparative study of the androgenic properties of progesterone and the progestins, medroxyprogesterone acetate (MPA) and norethisterone acetate (NET-A). J Steroid Biochem Mol Biol. 2014;143:404-415.

112. Louw-du Toit R, Hapgood JP, Africander D. Medroxyprogesterone acetate differentially regulates interleukin (IL)-12 and IL-10 in a human ectocervical epithelial cell line in a glucocorticoid receptor (GR)-dependent manner. J Biol Chem. 2014;289(45):31136-31149.

113. Arnold KB, et al. Increased levels of inflammatory cytokines in the female reproductive tract are associated with altered expression of proteases, mucosal barrier proteins, and an influx of HIV-susceptible target cells. Mucosal Immunol. 2016;9(1):194-205.

114. Segel GB, Halterman MW, Lichtman MA. The paradox of the neutrophil's role in tissue injury. J Leukoc Biol. 2011;89(3):359-372.

115. Anahtar MN, et al. Cervicovaginal bacteria are a major modulator of host inflammatory responses in the female genital tract. Immunity. 2015;42(5):965-976.

116. Sharkey DJ, Tremellen KP, Jasper MJ, GemzellDanielsson K, Robertson SA. Seminal fluid induces leukocyte recruitment and cytokine and chemokine mRNA expression in the human cervix after coitus. J Immunol. 2012;188(5):2445-2454.

117. Introini A, et al. Seminal plasma induces inflammation and enhances HIV-1 replication in human cervical tissue explants. PLoS Pathog. 2017;13(5):e1006402.

118. Joseph T, Zalenskaya IA, Sawyer LC, Chandra N, Doncel GF. Seminal plasma induces prostaglandin-endoperoxide synthase (PTGS) 2 expression in immortalized human vaginal cells: involvement of semen prostaglandin E2 in PTGS2 upregulation. Biol Reprod. 2013;88(1):13.

119. Lincoln C, Perera R, Jacobs I, Ward A. Macroscopically detected female genital injury after consensual and non-consensual vaginal penetration: a prospective comparison study. J Forensic Leg Med. 2013;20(7):884-901.

120. Hilber AM, et al. Intravaginal practices, vaginal infections and HIV acquisition: systematic review and meta-analysis. PLoS One. 2010;5(2):e9119.

121. Low N, et al. Intravaginal practices, bacterial vaginosis, and HIV infection in women: individual participant data meta-analysis. PLoS Med. 2011;8(2):e1000416.

122. Cohen CR, et al. Increased levels of immune activation in the genital tract of healthy young women from sub-Saharan Africa. AIDS. 2010;24(13):2069-2074.

123. Fettweis JM, et al. Differences in vaginal microbiome in African American women versus women of European ancestry. Microbiology. 2014; 160(pt 10):2272-2282.

124.Passmore JA, Jaspan HB, Masson L. Genital inflammation, immune activation and risk of sexual HIV acquisition. Curr Opin HIV AIDS. 2016;11(2):156-162.

125. Mitchell C, et al. Associations between genital tract infections, genital tract inflammation, and cervical cytobrush HIV-1 DNA in US versus Kenyan women. J Acquir Immune Defic Syndr. 2013;62(2):143-148.

126. Thurman AR, et al. Comparison of follicular and luteal phase mucosal markers of HIV susceptibility in healthy women. AIDS Res Hum Retroviruses. 2016;32(6):547-560.

127. Zalenskaya IA, et al. Gene expression profiling of human vaginal cells in vitro discriminates compounds with pro-inflammatory and mucosaaltering properties: novel biomarkers for preclinical testing of HIV microbicide candidates. PLoS One. 2015;10(6): 0128557. 